\title{
Assessment of Modeling and Nuclear Data Needs for Active Neutron Interrogation
}

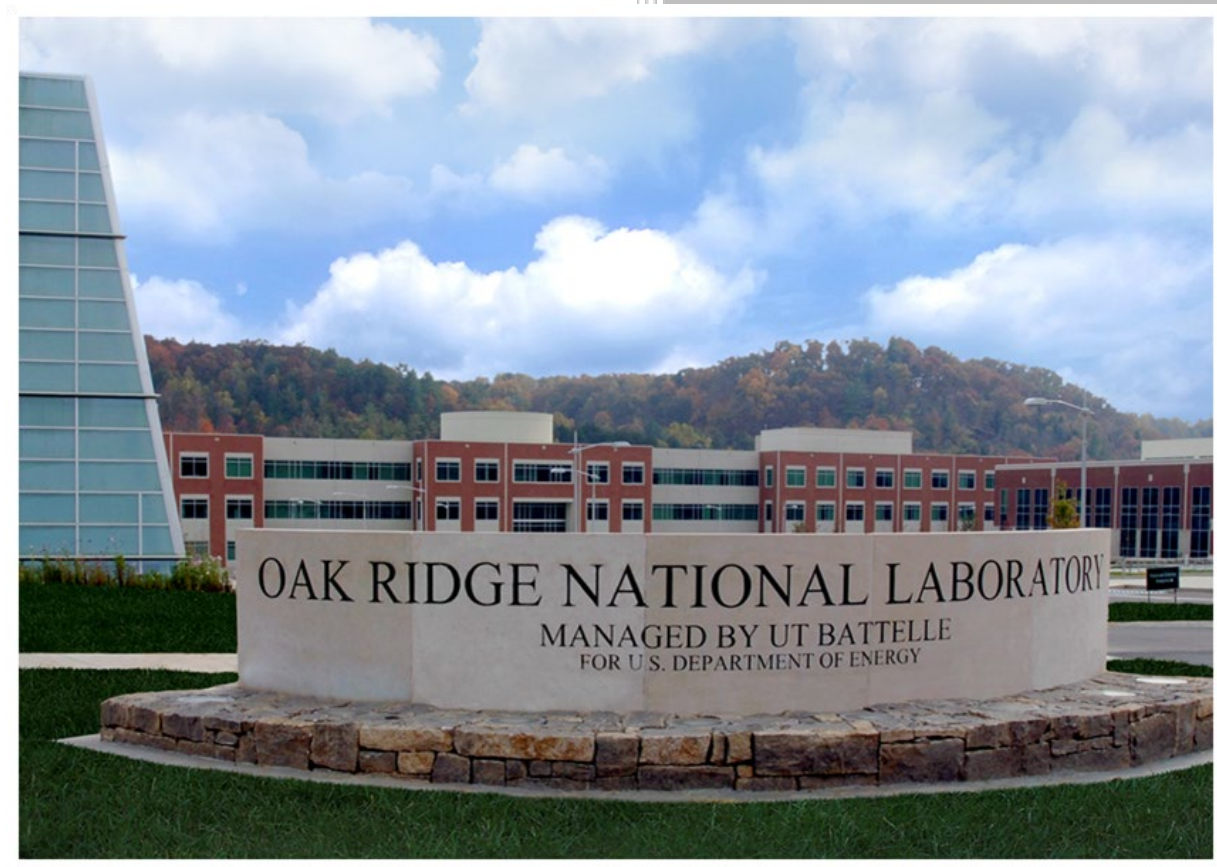

Approved for public release. Distribution is unlimited.

Seth McConchie Lee Bernstein Matthew Blackston David Brown Bonnie Canion Catherine Romano Jerome Verbeke

April 2021 


\section{DOCUMENT AVAILABILITY}

Reports produced after January 1, 1996, are generally available free via US Department of Energy (DOE) SciTech Connect.

Website www.osti.gov

Reports produced before January 1, 1996, may be purchased by members of the public from the following source:

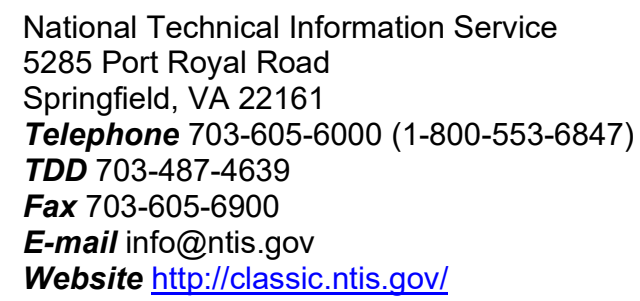

Reports are available to DOE employees, DOE contractors, Energy Technology Data Exchange representatives, and International Nuclear Information System representatives from the following source:

Office of Scientific and Technical Information

PO Box 62

Oak Ridge, TN 37831

Telephone 865-576-8401

Fax 865-576-5728

E-mail reports@osti.gov

Website http://www.osti.gov/contact.html

This report was prepared as an account of work sponsored by an agency of the United States Government. Neither the United States Government nor any agency thereof, nor any of their employees, makes any warranty, express or implied, or assumes any legal liability or responsibility for the accuracy, completeness, or usefulness of any information, apparatus, product, or process disclosed, or represents that its use would not infringe privately owned rights. Reference herein to any specific commercial product, process, or service by trade name, trademark, manufacturer, or otherwise, does not necessarily constitute or imply its endorsement, recommendation, or favoring by the United States Government or any agency thereof. The views and opinions of authors expressed herein do not necessarily state or reflect those of the United States Government or any agency thereof. 
Physics Division

\title{
Assessment of Modeling and Nuclear Data Needs for Active Neutron Interrogation
}

\author{
Seth McConchie ${ }^{1}$ \\ Lee Bernstein ${ }^{2}$ \\ Matthew Blackston ${ }^{3}$ \\ David Brown ${ }^{4}$ \\ Bonnie Canion ${ }^{5}$ \\ Catherine Romano ${ }^{6}$ \\ Jerome Verbeke ${ }^{5}$
}

Date Published: April 2021

\author{
Prepared by \\ OAK RIDGE NATIONAL LABORATORY \\ Oak Ridge, TN 37831-6283 \\ managed by \\ UT-BATTELLE, LLC \\ for the \\ US DEPARTMENT OF ENERGY \\ under contract DE-AC05-00OR22725
}

${ }^{1}$ Oak Ridge National Laboratory

${ }^{2}$ Lawrence Berkeley National Laboratory

${ }^{3}$ Previously Oak Ridge National Laboratory, now Two Six Labs

${ }^{4}$ Brookhaven National Laboratory

${ }^{5}$ Lawrence Livermore National Laboratory

${ }^{6}$ Previously Oak Ridge National Laboratory, now IB3 Global Solutions 



\section{EXECUTIVE SUMMARY}

This document is the primary deliverable for a scoping study proposed to DOE National Laboratory Announcement Number LAB 19-2114 in the NNSA research area. The study supports user applications employing active neutron interrogation by providing a science plan to improve the modeling capability and the nuclear data that radiation transport codes use. Users rely on the accuracy of the elastic scattering and non-elastic cross-sections spanning thermal energies to $14 \mathrm{MeV}$ (and higher in some cases) for modeling the neutron transport through complex geometries of materials potentially composed of many elements. While the elastic scattering cross-section data are accepted for all commonly occurring elements, the non-elastic cross-section data and the associated emission data include reaction channels that require attention. The study focused on the non-elastic reactions that emit secondary, also known as prompt, gammas with the premise that many users would benefit from improved modeling of these reactions. Many users develop material assay technologies based upon gamma signatures from radiative capture, inelastic scattering, and reactions on low- $Z$ isotopes emitting multiple particles, so the nuclear data gaps, modeling deficiencies, and recommendations for addressing the shortfalls were assessed for these reactions. Fission gammas were excluded from this study because there are other efforts underway to address known shortfalls. Follow-on efforts that successfully execute the recommendations will tangibly improve to the ability to model gamma signatures and backgrounds for user applications, such as controlled substance detection, oil-well logging, and space exploration.

The modeling deficiencies were identified by partitioning users into two groups and assuming that deficiencies with Geant4 and MCNP6 ${ }^{\circledR}$ adequately cover deficiencies with other commonly used radiation transport codes like SCALE and TRIPOLI ${ }^{\circledR}$. Users in the first group (User Group \#1) require the number of absorption or scattering reactions and the number and energies of emitted gammas to be correct on average over many source neutrons, while users in the second group (User Group \#2) require the emission energy, time, number, and angle information for neutrons and gammas to be accurate on an event-by-event basis. For User Group \#1, MCNP6 ${ }^{\circledR}$ and Geant4 are sufficient for these users' needs if the reaction data are available in the ENDF libraries. For User Group \#2, MCNP6 ${ }^{\circledR}$ and Geant4 are not sufficient for these users' needs. $\mathrm{MCNP6}^{\circledR}$ can correlate neutrons and gammas with a supplementary code known as Cascading Gamma-ray Multiplicity (CGM), but there are issues with the physics and computational implementation. Geant4 correlates neutrons and gammas, but the gamma production cross-section and gamma multiplicity data must exist for excitations to the discrete states. Also, Geant4 modeling of excitations to the continuum of states is unreliable because energy and momentum are not conserved. This deficiency is important for users who employ several-MeV neutron sources (e.g., D-T neutron generators), which excite many nuclei to the continuum with high likelihood.

A data discovery effort was performed with six ENDF libraries to determine what gamma production cross-section and gamma emission data are available for users, if the nuclear data exist, to ensure that radiation transport codes meet user needs. A list of elements was constructed to constrain the scope of this effort according to categories of materials that users commonly need to model. Depending upon the library, several elements in the list do not have the gamma emission probabilities in the format required to reproduce cascades from reactions that can leave the residual nucleus in an excited state. Similarly, gamma spectral data on which some users rely are either spread across multiple data blocks or not available for some less commonly considered elements. The ENSDF database has gamma emission data (namely gamma transition energies, relative intensities, and final levels after transitions) not available in the ENDF libraries, but there must be cross-section data for such data to be useful. As for the quality of the cross-section or gamma emission data, a comprehensive assessment was not 
performed in this effort. However, there are documented instances of measurement and modeling discrepancies, as well as examples of a complete absence of correlated neutron-induced gamma-ray data that may be used as a starting point for follow-on experimental efforts.

The study recommendations to address these shortfalls are:

1. Reconcile the discrete gamma energies and emission probabilities between the ENDF/B-VIII.0 library and the ENSDF library.

2. Reconcile the primary and secondary (e.g., prompt) gamma spectral data between the ENDF/BVIII.0 library and the ENSDF library.

3. Extend the Generalized Nuclear Database Structure (GNDS) to include the level density information and allow states to be embedded in the continuum.

4. Develop a computationally practical gamma event generator for modeling excitations to the continuum and incorporate it into any radiation transport code that can model event-by-event processes.

5. Correct existing and fill in missing reaction cross-section data (thermal to $14 \mathrm{MeV}$ ) and gamma emission data with the following steps:

a. Review existing reaction cross-section data and gamma emission data using existing experimental datasets to identify inaccuracies or gaps.

b. Assess any existing data previously not considered for inclusion into ENSDF and ENDF/BVIII.0 to correct inaccuracies or fill in gaps.

c. Perform new reaction cross-section measurements from thermal to $14 \mathrm{MeV}$, as needed.

d. Incorporate any new data into ENSDF and ENDF/B-VIII.O.

6. Engage with users to assess any improvement in the ability to model secondary gamma emissions.

Any effort to reconcile the data contained within ENDF/B-VIII.0 and ENSDF should be performed on all elements in the list used for the data discovery effort. As there are 46 elements in the list, it was broken into tiers to constrain near-term experimental efforts. This breakdown was developed by subjectively determining the importance of each element to all users and assuming that the nuclear data for each element require some improvement. However, some elements may require minimal experimental effort if the cross-sections for any reaction that can result in gamma emission are sufficiently available in the ENDF libraries such as ENDF/B-VIII.0. For new experimental efforts, these elements may be useful to demonstrate the experimental validity to address incomplete or inaccurate data for other elements.

This document is organized to provide a science plan for future work to improve the modeling capability and nuclear data. The plan describes the utility of secondary gamma emissions from active neutron interrogation, the justification for modeling these emissions, the modeling deficiencies and nuclear data gaps, and the recommendations for addressing the shortfalls. The appendices provide supporting information regarding how secondary gamma emissions are modeled in commonly used radiation transport codes, references to applications that use secondary gamma emissions, examples of modeling and measurement discrepancies, and the availability of secondary gamma emission data in the ENDF libraries. 


\section{CONTENTS}

FIGURES

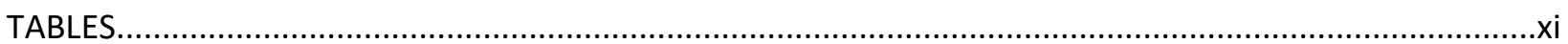

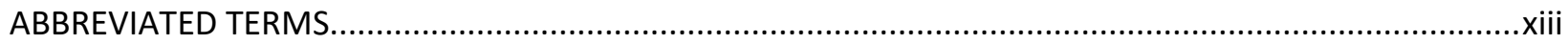

1. OVERVIEW

2. UTILITY OF SECONDARY GAMMA EMISSIONS FROM ACTIVE NEUTRON INTERROGATION ................. 2

3. JUSTIFICATION FOR MODELING SECONDARY GAMMA EMISSIONS …........................................... 3

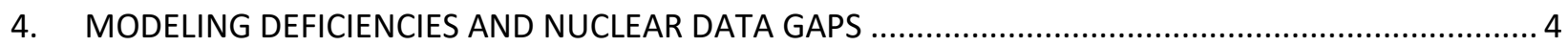

5. RECOMMENDATIONS FOR ADDRESSING THE DEFICIENCIES AND GAPS .................................... 6

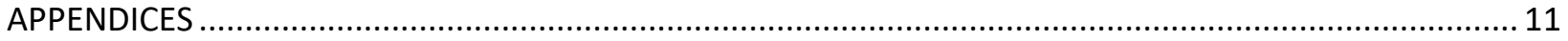

APPENDIX A. Secondary Gamma Emission Modeling in Commonly Used Radiation Transport Codes.......

APPENDIX B. References to Applications that Utilize Secondary Gamma Emissions ....................... B-1

APPENDIX C. Examples of Measurement Data and Modeling Discrepancies....................................

APPENDIX D. Availability of Secondary Gamma Emission Data in ENDF Libraries .......................... D-1 



\section{FIGURES}

Figure C-1. Time distribution of events after alpha detection. A description of the numbered features can be found in the text.

Figure C-2. (a) Pixelated plastic scintillator (EJ-200) array, (b) API D-T neutron generator, (c) data acquisition enclosure, and (d) arrangement HDPE, steel, and tungsten annuli.

Figure C-3. Feature corresponding to total induced gammas for the (left) HDPE annulus, (middle) steel annulus, and (right) tungsten annulus.

Figure C-4. Neutron time-of-flight distribution for gamma-neutron correlations associated with an alpha event for the (left) HDPE annulus, (middle) steel annulus, and (right) tungsten annulus.

Figure C-5. Gamma pulse height spectra for the gamma-neutron correlations associated with an alpha event for the (left) HDPE annulus, (middle) steel annulus, and (right) tungsten annulus. 



\section{TABLES}

Table 1. Status of the modeling and nuclear data for User Group \#1 and User Group \#2....................... 5

Table 2. Recommended activities, what they address, and any relevant notes. ..................................... 7

Table 3. All elements of interest by material category. The updates to the gamma emission data should be performed for all elements listed in this table. ...................................................... 10

Table 4. List of priority elements by tier to further prioritize the experimental work. These tiers should be allowed to evolve as the nuclear data libraries improve.

Table A-1. Data block, or file (MF), descriptions in the ENDF-6 format. The MF relevant to secondary gamma emission are highlighted.

Table A-2. Reaction identifiers (MT) relevant to secondary gamma emissions from neutron inelastic scattering and neutron capture.

Table A-3. Data description and notes for the MF relevant to secondary gamma emission. The most important notes are shown in bold typeface.

Table A-4. Ability for the ENDF libraries to support the needs of User Group \#1 and User Group

\#2. The most important notes are shown in bold typeface.

Table A-5. Summary of the MCNP6.2 and Geant4.10 capabilities for modeling secondary gamma emissions. The most important notes are shown in bold typeface.

Table B-1. Brief list of applications that utilize secondary gamma emissions. The list of references is intended to provide a starting point for examining a particular application.

Table C-1. An assessment of the modeled and measured gamma spectra agreement for the oilwell logging industry.

Table D-1. ENDF libraries evaluated for the availability of secondary gamma emission data.

Table D-2. Data discovery results for inelastic scattering to the low excited states for the tier 1 elements.

Table D-3. Data discovery results for inelastic scattering to the low excited states for the tier 2 elements.

Table D-4. Data discovery results for inelastic scattering to the low excited states for the tier 3 elements.

Table D-5. List of available MTs for $M F=3, M F=6$, and MF=12 in ENDF/B-VIII.0 for the tier 1 priority elements.

Table D-6. List of available MTs for $\mathrm{MF}=3, \mathrm{MF}=6$, and $\mathrm{MF}=12$ in $\mathrm{ENDF} / \mathrm{B}-\mathrm{VIII} .0$ for the tier 2 priority elements.

Table D-7. List of available MTs for $M F=3, M F=6$, and MF=12 in ENDF/B-VIII.0 for the tier 3 priority elements.

Table D-8. List of available MTs for MF=3, MF=6, and MF=12 in TENDL-2019 for the tier 1 priority elements.

Table D-9. List of available MTs for MF=3, MF=6, and MF=12 in TENDL-2019 for the tier 2 priority elements.

Table D-10. List of available MTs for MF=3, MF=6, and MF=12 in TENDL-2019 for the tier 3 priority elements.

Table D-11. Breakup reaction flags in the ENDF libraries. 



\section{ABBREVIATED TERMS}

\begin{tabular}{|c|c|}
\hline ABS & Acrylonitrile Butadiene Styrene \\
\hline $\mathrm{AmBe}$ & Americium Beryllium \\
\hline AmLi & Americium Lithium \\
\hline API & Associated Particle Imaging \\
\hline ASA & Acrylonitrile Styrene Acrylate \\
\hline BGO & Bismuth Germanium Oxide or Bismuth Germanate \\
\hline BNL & Brookhaven National Laboratory \\
\hline BROND & Russian ENDF library \\
\hline CEA & The French Alternative Energies and Atomic Energy Commission \\
\hline CENDL & Chinese Evaluated Nuclear Data Library \\
\hline CGM & Cascading Gamma-ray Multiplicity \\
\hline D-D & Deuterium-Deuterium \\
\hline D-T & Deuterium-Tritium \\
\hline ENDF & Evaluated Nuclear Data File \\
\hline ENDF/B-VIII.0 & ENDF Version B, Major Release 8, Minor Release 0 \\
\hline ENDF-6 & ENDF data format \\
\hline ENSDF & Evaluated Nuclear Structure Data File \\
\hline Geant & Geometry and Tracking radiation transport software platform \\
\hline GNDS & Generalized Nuclear Database Structure \\
\hline HDPE & High-Density Polyethylene \\
\hline High-Z & High atomic number \\
\hline HPGe & High-Purity Germanium \\
\hline JEFF & Joint Evaluated Fission and Fusion nuclear data library \\
\hline JENDL & Japanese Evaluated Nuclear Data Library \\
\hline keV & kilo-electronvolt \\
\hline $\mathrm{LaBr}$ & Lanthanum Bromide \\
\hline LBNL & Lawrence Berkeley National Laboratory \\
\hline LLNL & Lawrence Livermore National Laboratory \\
\hline LR & ENDF-6 residual breakup flag \\
\hline MCNP ${ }^{\circledR}$ & Monte Carlo N-Particle ${ }^{\circledR}$ transport code \\
\hline $\mathrm{MeV}$ & Mega-electronvolt \\
\hline MF & ENDF-6 data block or file \\
\hline MT & ENDF-6 reaction nomenclature \\
\hline Nal & Sodium lodide \\
\hline ORNL & Oak Ridge National Laboratory \\
\hline PLA & Polylactic Acid \\
\hline PMT & Photomultiplier Tube \\
\hline SCALE & Standardized Computer Analyses for Licensing Evaluation radiation transport code \\
\hline SNM & Special Nuclear Materials \\
\hline TENDL & Evaluated nuclear data library based upon the TALYS code system \\
\hline TPE & Thermoplastic Elastomer \\
\hline TPU & Thermoplastic Polyurethane \\
\hline TRIPOLI ${ }^{\circledR}$ & Family of Monte Carlo radiation transport codes developed by CEA \\
\hline
\end{tabular}




\section{OVERVIEW}

This document is the primary deliverable of a scoping study to assess the nuclear data and modeling needs for secondary ${ }^{7}$, also known as prompt, gamma emissions (excluding fission) from active neutron interrogation. The primary objective of this document is to provide recommendations for follow-on work to address the deficiencies of modeling secondary gamma emissions and gaps in the nuclear data that existing models employ. To accomplish this objective, this document is structured as follows:

- Utility of secondary gamma emissions from active neutron interrogation $\{$ Section 2$\}$ Why consider secondary gamma emissions at all?

- Justification for modeling secondary gamma emissions \{Section 3\} Why is modeling these emissions a useful activity?

- Modeling deficiencies and nuclear data gaps \{Section 4\} What are the current deficiencies in modeling these emissions and the gaps in the input nuclear data?

- Follow-on work recommendations for addressing the deficiencies and gaps $\{$ Section 5$\}$ How should the deficiencies and gaps be addressed?

The appendices contain the following information:

- Secondary gamma emissions modeling in commonly used radiation transport codes \{Appendix A\} How do commonly used radiation transport codes model secondary gamma emission using existing Evaluated Nuclear Data File (ENDF) libraries?

- References to applications that utilize secondary gamma emissions $\{$ Appendix B What applications rely on or would benefit from modeling of secondary gamma emissions?

- Examples of measurement data and modeling discrepancies \{Appendix $\mathrm{C}\}$ What are examples of measurement data and modelling discrepancies?

- Availability of secondary gamma emissions data in the ENDF libraries \{Appendix D\} What secondary gamma emission data are available and how are the data organized for common isotopes?

In the study, the effort focused upon secondary gammas emitted from inelastic scattering and radiative capture. While induced fission gammas may be considered secondary gamma emissions, other efforts have completed or are underway to address modeling deficiencies and nuclear data gaps.

\footnotetext{
${ }^{7}$ In this document, "secondary gamma" implies the context of radiation transport whereby source neutrons are "primary" transported particles and gammas emitted from neutron interactions are "secondary" transported particles. Although delayed gammas and other particles may be emitted, prompt gammas are the focus of this document.
} 


\section{UTILITY OF SECONDARY GAMMA EMISSIONS FROM ACTIVE NEUTRON INTERROGATION}

Summary: Secondary gamma emissions from active neutron interrogation provide a physical mechanism for unambiguously assessing the isotopic composition of an object (i.e., material identification).

Support: When neutrons impinge on an object, an incoming neutron can interact with a nucleus by scattering or absorption, sometimes leaving the residual nucleus in an excited state, which can subsequently decay via particle and/or gamma-ray emission. As the nucleus de-excites to the ground state, a cascade of one or more gammas are emitted. Each emitted gamma has an energy equal to the difference between two states during the de-excitation process. Each isotope has a unique structure of states such that a neutron source can induce gammas characteristic to the isotopic composition of an object. For example, sodium hypochlorite (i.e., bleach) can be distinguished from other materials by detecting the $0.472 \mathrm{MeV}$ emission from radiative capture $(n, \gamma)$ on ${ }^{23} \mathrm{Na}$, the $1.16 \mathrm{MeV}$ emission from ${ }^{35} \mathrm{Cl}(n, \gamma){ }^{36} \mathrm{Cl}$, and the $6.13 \mathrm{MeV}$ emission from inelastic scattering $\left(n, n^{\prime} \gamma\right)$ on ${ }^{16} \mathrm{O}$.

This technique has been applied to bulk material assay where X-ray resonance fluorescence is infeasible. For example, the Portable Isotopic Neutron Spectroscopy system uses this technique for explosives detection and chemical warfare agent detection. In the oilfield industry this technique provides a means of characterizing the oil well environment during hydrocarbon exploration. Applications employing this technique may include the following:

- Controlled substance detection: The detection of bulk quantities of explosives, chemical warfare agents, narcotics, and special nuclear materials has been an ongoing research and development effort by several private and government organizations for the last few decades.

- Oil-well logging: Exploration to discover fossil fuel reservoirs requires a thorough elemental characterization of the subsurface.

- Planetary defense: The ability to deflect an inbound object (e.g., asteroid) from space depends on maximizing energy transfer via the choice of the appropriate incident neutron-induced reaction from a nuclear detonation.

- Space exploration: Measuring the chemical composition of objects or surfaces in extraterrestrial environments is part of the space exploration mission.

- Emergency response: The response to an unknown object could be influenced by an assessment of its elemental composition.

- Arms control/treaty verification: The presence and quantity of certain materials, such as high explosives, may be considered as a verification element in a monitoring regime.

References for relevant applications can be found in Appendix B. 


\section{JUSTIFICATION FOR MODELING SECONDARY GAMMA EMISSIONS}

Summary: Modeling secondary gamma emissions enables the ability to:

- Scope physics limitations

What gamma signatures are observable for a given measurement time?

- Optimize system design parameters

How should the core system components be arranged given application constraints?

- Develop analysis algorithms

What is the best algorithm for translating a detector signal to a useful quantity?

These activities can be cost-prohibitive or time-prohibitive with measurements alone.

Support: The traditional neutron-induced gamma spectrometry measurement involves a neutron source (e.g., ${ }^{252} \mathrm{Cf}, \mathrm{AmBe}, \mathrm{D}-\mathrm{D}$ neutron generator, D-T neutron generator) and an array of gamma detectors (e.g., Nal, BGO, LaBr, HPGe). A gamma event in the detector is translated to a pulse height that is proportional to the gamma energy. The pulse height spectrum enables an analysis of the peaks to determine what isotopes are present within an object. Most peaks correspond to emitted gammas at discrete energies from radiative capture $(n, \gamma)$, inelastic scattering $\left(n, n^{\prime} \gamma\right)$, or reactions with multiple particle emissions in the case of low-Z elements, e.g., $(n, p n \gamma),(n, \alpha n \gamma)$, etc. The reaction channel that proves most useful depends primarily on the effective cross-section for a particular peak. Additional analysis is possible with the Compton continuum to enhance the isotopic analysis. Such an analysis involves comparing a spectrum to a source library based upon an extensive measurement dataset or very accurate simulations.

An additional objective can be the quantification of the ratios of signals (e.g., peak counts) to classify the present material. The inferred signal ratios depend upon the stoichiometric ratios of a material and provide a method of distinguishing between classes of materials. For example, melamine $\left(\mathrm{C}_{3} \mathrm{H}_{6} \mathrm{~N}_{6}\right)$ may be distinguishable within a stream of objects. If a sufficiently energetic neutron source is not used to enable the detection of the $6.13 \mathrm{MeV}$ gamma from ${ }^{16} \mathrm{O}\left(n, n^{\prime} \gamma\right)$, an explosives detection system will need to assess the ratio of $\mathrm{C} / \mathrm{N}$ or $\mathrm{H} / \mathrm{N}$ to prevent false positives from melamine. The ability to draw a meaningful conclusion from signal ratios can require a sophisticated treatment of the transmission of neutrons through the object, self-attenuation of the induced gammas, the differences in efficiency between the gamma energies, and the cross-section data. While the development of the analysis algorithm may be based upon first principles, the final analysis algorithm may include radiation transport models to minimize systematic errors. These models rely on nuclear data, namely gamma production cross-section data as a function of energy as well as branching ratios and gamma energies for state transitions.

The prior described approach to measure secondary gamma emissions primarily operates in the energy domain. An alternative measurement approach uses a very short-pulse neutron generator or an associated particle imaging (API) neutron generator and operates in the time domain. Secondary gamma events are correlated in time with the source pulse or source event on the nanosecond time scale. If special nuclear materials (SNM) are present, induced fission neutrons and gammas will also be correlated with the source event. For a material identification algorithm that seeks to detect SNM with fission gamma emissions when shielding is present, the algorithm must account for cascades of gammas 
that can occur from inelastic scattering. These cascades act as a background for a signal based upon multiplicities of fission gammas. Algorithm development requires modeling to assess the physics limitations of employing fission gammas for SNM detection. Such models rely on the same nuclear data as the models for the traditional neutron-induced gamma spectrometry approach. For these measurements, the number of gammas in a cascade are the primary data required, but energy is also important for modeling of detection efficiencies and thresholds accurately.

With an API neutron generator, the ability to correlate emitted neutrons and gammas to each source neutron gives the possibility that the locations of inelastic scattering events can be reconstructed within an object. As gammas emitted from inelastic scattering are unique to each isotope, inelastic scattering reconstructions along with elastic scattering and small angle scattering reconstructions may enable material identification in transmission images. Modeling will be required to scope the physics limitations of material identification from these reconstruction modalities, and these models rely on the same nuclear data.

\section{MODELING DEFICIENCIES AND NUCLEAR DATA GAPS}

Summary: The modeling deficiencies and nuclear data gaps depend upon the objective of measuring secondary gamma emissions. For this assessment the users are split into two groups. The first group (User Group \#1) measures the energies of secondary gamma emissions to perform material identification. The second group (User Group \#2) measures the correlations between scattered neutrons, gammas emitted from nuclear de-excitations, and source neutrons. Though radiation transport codes such as SCALE ${ }^{8}$ and TRIPOLI ${ }^{\otimes 9,10}$ were considered, this study assumes that the modeling deficiencies are sufficiently covered by exploring how Geant ${ }^{11}$ and $M C N P^{\circledR 12,13}$ model secondary gamma emission. The status of the modeling and nuclear data is given in Table 1. The general issues with the nuclear data pertained to some observed discrepancies between modeling and measurement with spectral data (User Group \#1), the incompleteness of the gamma emission data (User Group \#1 and \#2), and the inability to accurately model correlated neutrons and gammas from excitations to the continuum of states (User Group \#2).

\footnotetext{
${ }^{8}$ Wieselquist, W. A., Lefebvre, R. A., \& Jessee, M. A. (2020, April). SCALE Code System (ORNL/TM-2005/39 Version 6.2.4). Oak Ridge National Laboratory. https://doi.org/10.2172/1426571.

${ }^{9}$ TRIPOLI $^{\circledR}$ and TRIPOLI- $4{ }^{\circledR}$ are registered trademarks of The French Alternative Energies and Atomic Energy Commission (CEA).

${ }^{10}$ Brun, E., Damian, F., Diop, C., Dumonteil, E., Hugot, F., Jouanne, C., Lee, Y., Malvagi, F., Mazzolo, A., Petit, O., Trama, J., Visonneau, T., \& Zoia, A. (2015). TRIPOLI-4 ${ }^{\circledR}$, CEA, EDF and AREVA reference Monte Carlo code. Annals of Nuclear Energy, 82, 151-160. https://doi.org/10.1016/j.anucene.2014.07.053.

${ }^{11}$ Allison, J., Amako, K., Apostolakis, J., Arce, P., Asai, M., Aso, T., Bagli, E., Bagulya, A., Banerjee, S., Barrand, G., Beck, B., Bogdanov, A., Brandt, D., Brown, J., Burkhardt, H., Canal, P., Cano-Ott, D., Chauvie, .. Yoshida, H. (2016). Recent developments in Geant4. Nuclear Instruments and Methods in Physics Research Section A: Accelerators, Spectrometers, Detectors and Associated Equipment, 835, 186-225. https://doi.org/10.1016/j.nima.2016.06.125. ${ }^{12}$ MCNP $^{\circledast}$ and Monte Carlo N-Particle ${ }^{\circledast}$ are registered trademarks owned by Triad National Security, LLC, manager and operator of Los Alamos National Laboratory. For the purposes of visual clarity, the registered trademark symbol is assumed for all references to MCNP and its versions within this document. The use of "MCNP" and its variants in this document are shorthand for "MCNP code".

${ }^{13}$ Werner, C. J., Bull, J. S., Solomon, C. J., Brown, F. B., McKinney, G. W., Rising, M. E., Dixon, D. A., Martz, R. L., Hughes, H. G., Cox, L. J., Zukaitis, A. J., Armstrong, J. C., Forster, R. A., \& Casswell, L. (2018, February). MCNP Version 6.2 Release Notes (LA-UR-18-20808). Los Alamos National Laboratory. https://doi.org/10.2172/1419730.
} 
Table 1. Status of the modeling and nuclear data for User Group \#1 and User Group \#2.

\begin{tabular}{|c|c|c|}
\hline $\begin{array}{l}\text { User } \\
\text { Group }\end{array}$ & Modeling & Nuclear Data \\
\hline$\# 1$ & Geant4 and MCNP6.2 are sufficient & $\begin{array}{l}\text { Cross-section or gamma emission data are } \\
\text { known to be incomplete or inaccurate in } \\
\text { ENDF/B-VIII.0 (see Appendix C and Appendix D) }\end{array}$ \\
\hline \#2 & $\begin{array}{l}\text { Geant4 and MCNP6.2 are insufficient } \\
\text { Geant4: A simple event generator is used to } \\
\text { generate gammas from the input nuclear } \\
\text { data libraries. When the nuclear data are } \\
\text { adequate, this event generator is sufficient } \\
\text { for modeling the discrete state transitions } \\
\text { but does not adequately model the state } \\
\text { transitions from the quasi-continuum to } \\
\text { continuum. These high-level states are } \\
\text { accessible with a } 14 \text { MeV neutron source. } \\
\text { MCNP6.2: Neutrons and gammas from } \\
\text { inelastic scattering are not emitted in } \\
\text { coincidence without turning on the } \\
\text { Cascading Gamma-ray Multiplicity (CGM) } \\
\text { code. An average neutron binding energy is } \\
\text { used instead of the actual Q-value for a } \\
\text { reaction, and CGM slows down MCNP6.2 by } \\
\text { approximately a factor of } 1000 \text {. }\end{array}$ & $\begin{array}{l}\text { Cross-section data and gamma emission (e.g., } \\
\text { discrete energies and emission probabilities) } \\
\text { data are known to be incomplete in ENDF/B- } \\
\text { VIII.0 (see Appendix D). There are instances of } \\
\text { gamma emission data in the latest version of } \\
\text { the Evaluated Nuclear Structure Data File } \\
\text { (ENSDF) library that are not in ENDF/B-VIII.0. } \\
\text { The } 40 \text { excited state limitation in the ENDF-6 } \\
\text { format prevents all the ENSDF information } \\
\text { from being ported to ENDF libraries for many } \\
\text { nuclei and creates artifacts in the modeled } \\
\text { gamma spectrum. }\end{array}$ \\
\hline
\end{tabular}

Support: User Group \#1 performs the traditional neutron-induced gamma spectrometry measurement. This user group has the following modeling needs: in the average over many source neutrons, the number of absorption or scattering reactions is correct, and the number and energies of emitted gammas are correct. The modeling code must accurately sample the cross-section data for reactions emitting secondary gammas, perform the 2-body kinematics to determine the energy and direction of the outgoing neutron (inelastic scattering only), and sample the emitted gammas with the correct energy and probability of emission. These codes rely on the nuclear data compiled into the Evaluated Nuclear Data File (ENDF) libraries. Certain physics approximations can be performed where the emitted gammas do not correspond to the reaction that created them, but the gamma spectrum is correct over many source neutrons. The gamma spectrum is known as an average quantity. For this study Geant 4 and MCNP6.2 were evaluated for the ability to satisfy the needs of these users. If the cross-section data and gamma emission data (i.e., primary and secondary spectral data) are available and correct within the ENDF data libraries, then both codes meet the modeling needs. One exception is that Geant4 ignores the nucleus breakup ENDF flag by default, resulting in emission of unphysically high energy gammas because the compound nucleus is forced to decay without emitting alpha particles or other light ions. More information on this modeling deficiency can be found in Appendix A.

Although Geant4 and MCNP6.2 meet the modeling needs of User Group \#1, their predictive capability is limited by the input nuclear data in the ENDF data libraries. There are known instances of discrepancies between modeling results and measurement data. For example, MCNP simulations of the $2.31 \mathrm{MeV}$ 
gamma from ${ }^{14} \mathrm{~N}$ inelastic scattering agree with measurement data within an order of magnitude for one user ${ }^{14}$. Upon further inspection of the ENDF/B-VIII.0 library, the $2.31 \mathrm{MeV}$ gamma is not listed within any of the ENDF files that might have it, namely $M F=6, M F=12, M F=13$, or $M F=15$. For another user $^{15}, \mathrm{MCNP}$ simulations of iron revealed that several gammas between $2 \mathrm{MeV}$ and $5 \mathrm{MeV}$ from neutron capture are missing in ENDF/B-VIII.0.

User Group \#2 measures correlations in time between inelastically scattered neutrons, gammas emitted from state transitions during the de-excitation process, and source neutrons. These time correlation observables may offer signatures that can be used to perform material identification. Though these signatures are due primarily to gamma emissions from inelastic scattering, gamma emissions from absorption reactions, like radiative capture $(n, \gamma)$, should be considered to properly model background terms. In contrast to User Group \#1, this group relies on correct physics modeling of event-by-event processes. For time correlation signatures to be meaningful, the model must correlate neutrons and gammas. This requirement eliminates MCNP6.2 as an option because neutrons and gammas are not emitted in coincidence. While Geant4 emits neutrons and gammas in coincidence, its event generator is limited by (1) the available ENDF data for modeling excitations to discrete states and (2) the inability to accurately model excitations to the continuum of states. For example, the gamma emission data for ${ }^{184} \mathrm{~W}\left(n, n^{\prime} \gamma\right)$ are available in ENSDF for up to the $43^{\text {rd }}$ excited state, but ENDF/B-VIII.0 only has crosssection data and emission probability data for the $1^{\text {st }}$ through $6^{\text {th }}$ excited states. A further limitation manifests from the ENDF- 6 format limit of 40 excited states. ENDF/B-VIII.0 has cross-section data and emission probability data for inelastic scattering to the first 40 excited states of ${ }^{56} \mathrm{Fe}$. However, ENSDF has gamma emission data for the first 57 excited states. Either these extra 17 states are missing from ENDF/B-VIII.0 by virtue of the 40 excited state limit or they have been subsumed into the data related to the continuum of states.

The modeling deficiency regarding the continuum of states is apparent when $14 \mathrm{MeV}$ neutron sources are used. The continuum of states refers to the excited states at high excitation energies whose energies are unresolved in the nuclear data or inaccessible experimentally. Geant4 attempts to model gamma emissions from the continuum, but the algorithm violates energy and momentum conservation due to the excited energies being unknown. $14 \mathrm{MeV}$ neutrons are sufficiently energetic to excite nuclei to the continuum, so the emitted gammas are unphysical. According to ENDF/B-VIII.0, $84 \%$ of the total inelastic cross-section for ${ }^{56} \mathrm{Fe}$ at $14 \mathrm{MeV}$ corresponds to excitation to the continuum. Additional model complexity manifests with the quasi-continuum of states, which lies above the known discrete states and below the continuum. In the quasi-continuum, the nuclear properties of the states are synthetically calculated using the known level density and gamma-strength function formulas. The ideal algorithm would accurately model gamma emissions from the continuum through the quasi-continuum and discrete states to the ground state and be computationally practical.

\section{RECOMMENDATIONS FOR ADDRESSING THE DEFICIENCIES AND GAPS}

The recommended activities for addressing the modeling deficiencies and nuclear data gaps are listed in Table 2. Both types of users benefit from all recommended activities.

\footnotetext{
14 Personal communication with Ed Seabury from Idaho National Laboratory.

${ }^{15}$ Personal communication with Marie-Laure Mauborgne from Schlumberger.
} 
Table 2. Recommended activities, what they address, and any relevant notes.

\section{Recommended activity}

1. Reconcile discrete gamma energies and emission probabilities between ENDF/B-VIII.0 and ENSDF.

2. Reconcile the primary and secondary gamma spectral data between ENDF/B-VIII.0 and ENSDF.

3. Extend the Generalized Nuclear Database Structure (GNDS) to include the level density information and allow states to be embedded in the continuum.

4. Develop a computationally practical gamma event generator for modeling excitations to the continuum and incorporate it into any radiation transport code (e.g., Geant4) that can model event-by-event processes.

\section{What it addresses Notes}

Missing and

inaccurate gamma emission data in ENDF/B-VIII.O for modeling nonelastic scattering

- These data are currently spread among the MF=6, 12, and 13 files in the ENDF- 6 format for inelastic and other two-body reactions. These data should be moved to the $M F=12$ file.

- This activity:

- Can be performed independently of other activities but would benefit from quality assurance checks with benchmark datasets (See Activity \#5.a.)

- Benefits primarily those users who use lower energy neutron source ${ }^{252} \mathrm{Cf}, \mathrm{AmLi}$, and D-D neutron generators.

Missing and inaccurate gamma emission data in ENDF/B-VIII.O for modeling neutron capture

\section{ENDF-6 format} limitation of 40 excited states

- These data are spread among the MF=6, 12 , and 15 files in the ENDF6 format for neutron capture reactions.

- This activity can be performed independently of other activities but would benefit from quality assurance checks with benchmark datasets (See Activity \#5.a.)

- This extension enables primary gamma triggered cascades, including complete states up to the separation energy $S_{n}$, and transitions from other unresolved states.

- This activity:

- Can be performed independently of other activities but would benefit from quality assurance checks with benchmark datasets (See Activity \#5.a)

- Must be completed before the event generator development (See Activity \#4) can be completed.

\section{Modeling}

deficiency that radiation

transport codes cannot correctly
- This activity:

- Depends partly on the completion of the GNDS extension (See Activity \#3).

- Would benefit from quality assurance checks with benchmark datasets (See Activity \#5.a) 
5. Correct existing and fill in missing reaction crosssection data (thermal to $14 \mathrm{MeV}$ ) and gamma emission data with the following steps:

a. Review existing reaction cross-section data and gamma emission data using existing experimental datasets to identify inaccuracies or gaps.

b. Assess any existing data previously not considered for inclusion into ENSDF and ENDF/B-VIII.0 to correct inaccuracies or fill in gaps.

c. Perform new reaction cross-section measurements from thermal to $14 \mathrm{MeV}$, as needed.

d. Incorporate any new data into ENSDF and ENDF/B.

6. Engage with users to assess any improvement in the ability to model secondary gamma emissions. model the gamma

emissions for

excitations to the

continuum

Instances of

inaccurate or

missing cross-

section data or

gamma emission

data
O Has sub-tasking that can be completed independently of other activities.
- This activity:

- Provides quality assurance for activities \#1, \#2, \#3, and \#4.

- Should have user input via user modeling experiences (See Activity \#6).

- May require the fabrication of thin/thick targets with known elemental composition.

- Can be performed in parallel with other activities.
Need to involve users in the development of libraries that they use
- This activity:

- Provides users with an opportunity to check data library draft releases and event generator versions for accuracy.

- May involve users adjusting elastic/inelastic cross-section data in their models to gauge sensitivity of observables to cross-section adjustments.

- Should be performed as significant library drafts are available and versions of the event generator are available. 
To constrain the scope of follow-on efforts, a priority list of elements was identified based upon material categories relevant to the applications listed in Section 2. The material categories are shown in Table 3. Future library improvements not involving new measurements, such as reconciling the discrete gamma energies, gamma emission probabilities, and gamma spectral data between ENDF/B-VIII.0 and ENSDF, should be performed on all elements in Table 3. The data discovery effort in Appendix $D$ can serve as a guide for what data does not exist currently. An important note is that users rarely model isotopically enriched materials, excepting fissile materials. In the data discovery effort, isotopes with natural abundance of $1 \%$ or greater contributed to the results.

To constrain any experimental work, the priority list was further broken into three tiers, which are shown in Table 4. This breakdown was developed by subjectively determining the importance of each element to all users and assuming that the nuclear data for each element in Table 3 require some improvement. For the first tier, most users are concerned with organic materials (thus $\mathrm{H}, \mathrm{C}, \mathrm{N}$, and $\mathrm{O}$ ) either as signals from the interrogated object or as background from the surrounding environment. Similarly, the remaining elements, except $U$ and $\mathrm{Pu}$, occur as background from intervening, shielding, surrounding, or structural materials or as part of a commonly used source or detector technology. U and Pu were selected for the first tier because of their importance in SNM detection and the apparent technical difficulty in measuring their non-fission secondary gamma emissions. The elements in the follow-up tier were selected for their prevalence in shielding materials and/or detectors or for their roles in alloyed materials (e.g., $\mathrm{Cr}, \mathrm{Mn}$, and $\mathrm{Ni}$ in steel). The elements in the remaining tier were selected because of their importance to some, but not all, users.

A comprehensive assessment of the cross-section data or gamma emission data quality was not performed for the elements in Table 3, but user observed issues for some elements are documented in Appendix C. Users may model complex geometries with many elements and yet may be unable to identify the nuclear data origin of observed discrepancies between modeling and measurement (e.g., Is the data incomplete, inaccurate, or both?). User provided benchmark quality data is uncommon in the literature, so anecdotal experience was also considered for this study. Thus, the tiers should be considered a starting point and should be allowed to evolve depending upon current experimental capabilities and as users test improvements to nuclear data libraries. Such evolutions require iterative interactions between the experimenters, nuclear data evaluators, and the users. The recommended first step is the inclusion of missing cross-section and gamma emission data into ENDF/B-VIII and any obvious corrections to existing data (e.g., Fe). Users would then test new data evaluations with well understood measurement setups to inform evaluators and experimenters of further issues with crosssection data and gamma emission data quality. Follow-on steps would consist of revising nuclear data with experimental or reaction modeling efforts and user validation as needed. The first step also could include the examination of elements in a higher tier, such as Al, whose data may be acceptable currently. These elements could be used as standards for experimental setups to prove the feasibility to measure the data for other elements that may require attention. In parallel, experimenters could suggest revisions to the tiers based upon the technical difficulty to measure the nuclear data for each element, which was not assessed in this study. Some nuclear data for some elements, such as $\mathrm{N}$ or $\mathrm{O}$, may be difficult to measure if neutron reactions have extremely low cross-sections or if the elements must be included with other elements in a target. Elements whose relevant nuclear data that can be addressed with existing experimental capabilities regardless of where they appear in the tiers may merit a revision to the tiers. 
Table 3. All elements of interest by material category. The updates to the gamma emission data should be performed for all elements listed in this table.

\begin{tabular}{|c|c|c|}
\hline Category & Materials & Elements \\
\hline Structural & $\begin{array}{l}\text { Aluminum, Steel, 3D printing materials } \\
\left(\mathrm{ABS}^{16}, \mathrm{PLA}^{17}, \mathrm{TPE}^{18}, \mathrm{TPU}^{19}, \mathrm{ASA}^{20}\right)\end{array}$ & $\begin{array}{l}\mathrm{H}, \mathrm{C}, \mathrm{N}, \mathrm{O}, \mathrm{Al}, \mathrm{Si}, \mathrm{Ti}, \mathrm{Cr}, \mathrm{Mn}, \mathrm{Fe}, \mathrm{Ni} \\
\text { Mo, Sn }\end{array}$ \\
\hline Controlled Substances & $\begin{array}{l}\text { Explosives, Drugs, Chemical agents, Special } \\
\text { Nuclear Materials }\end{array}$ & $\mathrm{H}, \mathrm{C}, \mathrm{N}, \mathrm{O}, \mathrm{F}, \mathrm{P}, \mathrm{S}, \mathrm{Cl}, \mathrm{As}, \mathrm{U}, \mathrm{Np}, \mathrm{Pu}$ \\
\hline $\begin{array}{l}\text { Intervening, Shielding, } \\
\text { Surrounding }\end{array}$ & $\begin{array}{l}\text { Polyethylene, Water, Thermal-neutron } \\
\text { absorbers, Lead, Tungsten, Concrete }\end{array}$ & $\begin{array}{l}\mathrm{H}, \mathrm{Li}, \mathrm{Be}, \mathrm{B}, \mathrm{C}, \mathrm{O}, \mathrm{Na}, \mathrm{Mg}, \mathrm{Si}, \mathrm{K}, \mathrm{Ca} \\
\mathrm{Fe}, \mathrm{Cd}, \mathrm{Sb}, \mathrm{W}, \mathrm{Pb}, \mathrm{Bi}\end{array}$ \\
\hline Detector & $\begin{array}{l}\text { Organic scintillators, Inorganic scintillators, } \\
\text { Semiconductors, Detector housing, } \\
\text { Photomultiplier tubes (PMTs) }\end{array}$ & $\begin{array}{l}\mathrm{H}, \mathrm{He}, \mathrm{C}, \mathrm{O}, \mathrm{Na}, \mathrm{Al}, \mathrm{Si}, \mathrm{Cl}, \mathrm{Ar}, \mathrm{Ni}, \mathrm{Ge}, \\
\mathrm{Br}, \mathrm{Kr}, \mathrm{l}, \mathrm{Xe}, \mathrm{Cs}, \mathrm{La}, \mathrm{Gd}, \mathrm{Bi}\end{array}$ \\
\hline Source & Housing, Source reaction elements & $\mathrm{Li}, \mathrm{Be}, \mathrm{Al}, \mathrm{Cr}, \mathrm{Fe}, \mathrm{Ni}, \mathrm{Cu}, \mathrm{Pu}, \mathrm{Am}$ \\
\hline
\end{tabular}

Table 4. List of priority elements by tier to further prioritize the experimental work. These tiers should be allowed to evolve as the nuclear data libraries improve.

\section{Experimental \\ Priority}

First $\quad \mathrm{H}, \mathrm{C}, \mathrm{N}, \mathrm{O}, \mathrm{Na}, \mathrm{Al}, \mathrm{Si}, \mathrm{Fe}, \mathrm{Cu}, \mathrm{Pb}, \mathrm{W}, \mathrm{U}, \mathrm{Pu}$

Follow-up $\mathrm{He}, \mathrm{Li}, \mathrm{Be}, \mathrm{B}, \mathrm{Cl}, \mathrm{Cr}, \mathrm{Mn}, \mathrm{Ni}, \mathrm{Ge}, \mathrm{Br}, \mathrm{Cd}, \mathrm{I}, \mathrm{Cs}$, La

Remaining $\mathrm{F}, \mathrm{Mg}, \mathrm{P}, \mathrm{S}, \mathrm{Ar}, \mathrm{K}, \mathrm{Ca}, \mathrm{Ti}, \mathrm{As}, \mathrm{Kr}, \mathrm{Mo}, \mathrm{Sn}, \mathrm{Sb}, \mathrm{Xe}, \mathrm{Gd}, \mathrm{Bi}, \mathrm{Np}, \mathrm{Np}, \mathrm{Am}$

${ }^{16}$ Acrylonitrile butadiene styrene

17 Polylactic acid

18 Thermoplastic elastomer

19 Thermoplastic polyurethane

${ }^{20}$ Acrylonitrile styrene acrylate 
APPENDICES 


\section{APPENDIX A. Secondary Gamma Emission Modeling in Commonly Used Radiation Transport Codes}

This appendix leverages a series of presentations ${ }^{21,22,23}$ developed by one of the authors to assess the current modeling capability and nuclear data availability for applications that rely on spontaneous fission emissions or active-induced neutron or gamma signatures to perform material identification. Modeling the relevant nuclear reactions usually spans thermal energies to $14 \mathrm{MeV}$ in radiation transport codes such as MCNP6.2 and Geant4.10. This appendix has the following objectives:

1. Summarize the physics underlying gamma emission from neutron inelastic scattering and neutron capture ${ }^{24}$

2. Present how commonly used radiation transport codes use the ENDF libraries to model the physics

3. Identify the current modeling deficiencies and the role of the ENDF- 6 format in these deficiencies

\section{Brief Description of Secondary Gamma Emission Physics}

This section briefly summarizes the physics of secondary, also known as prompt, gamma emission, from neutron inelastic scattering and neutron capture. Only the relevant physics for user modeling purposes is covered.

When an incident neutron inelastically scatters off a nucleus ${ }_{Z}^{A} X$, the nucleus and incident neutron form an excited compound nucleus ${ }_{\mathrm{Z}}^{\mathrm{A}+1} \mathrm{X}^{*}$, which then decays to the excited nucleus ${ }_{\mathrm{Z}}^{\mathrm{A}} \mathrm{X}^{*}$. The final excited nucleus transitions between states with the emission of a gamma until reaching the ground state. The number of emitted gammas can be one only, such as the following transition for ${ }^{12} \mathrm{C}$ :

$$
n+{ }^{12} \mathrm{C} \rightarrow{ }^{13} \mathrm{C}^{*} \rightarrow{ }^{12} \mathrm{C}^{*}(4439.82 \mathrm{keV}) \rightarrow{ }^{12} \mathrm{C}+\gamma(4438.94 \mathrm{keV})
$$

In this example, a single 4.4 MeV gamma is emitted from the reaction. Alternatively, multiple, or a cascade of, gammas could be emitted, such as the following set of transitions for ${ }^{14} \mathrm{~N}$ :

$$
\begin{aligned}
n+{ }^{14} \mathrm{~N} \rightarrow{ }^{15} \mathrm{~N}^{*} & \rightarrow{ }^{14} \mathrm{~N}^{*}(5834.25 \mathrm{keV}) \rightarrow{ }^{14} \mathrm{~N}^{*}(5105.89 \mathrm{keV})+\gamma(728.34 \mathrm{keV}) \\
& \rightarrow{ }^{14} \mathrm{~N}^{*}(2312.80 \mathrm{keV})+\gamma(2792.80 \mathrm{keV}) \rightarrow{ }^{14} \mathrm{~N}+\gamma(2312.59 \mathrm{keV})
\end{aligned}
$$

In this example, three gammas with energies $0.7 \mathrm{MeV}, 2.3 \mathrm{MeV}$, and $2.8 \mathrm{MeV}$ are emitted, though this set of transitions is not the only set possible. An alternative set of transitions starting from ${ }^{14} \mathrm{~N}^{*}(5834.25 \mathrm{keV})$ could be:

\footnotetext{
${ }^{21}$ Verbeke, J. (2018, January). Monte Carlo Simulations and Nuclear Data (LLNL-PRES-744430). Livermore, CA: Lawrence Livermore National Laboratory.

22 Verbeke, J. (2019, December). Monte Carlo Simulations and Nuclear Data (Unpublished presentation). Livermore, CA: Lawrence Livermore National Laboratory.

${ }^{23}$ Verbeke, J. (2020, March). Active Neutron Interrogation Scoping Study (LLNL-PRES-807673). Livermore, CA: Lawrence Livermore National Laboratory.

${ }^{24}$ As stated in the overview section, though induced fission gammas may be considered secondary gamma emissions, they are not considered in this report.
} 


$$
\begin{gathered}
n+{ }^{14} \mathrm{~N} \rightarrow{ }^{15} \mathrm{~N}^{*} \rightarrow{ }^{14} \mathrm{~N}^{*}(5834.25 \mathrm{keV}) \rightarrow{ }^{14} \mathrm{~N}^{*}(5105.89 \mathrm{keV})+\gamma(728.34 \mathrm{keV}) \\
\rightarrow{ }^{14} \mathrm{~N}+\gamma(5104.89 \mathrm{keV})
\end{gathered}
$$

with two gammas emitted instead. Using the transition probabilities from the Evaluated Nuclear Structure Data File (ENSDF) file for ${ }^{14} \mathrm{~N}$, the former set of transitions would occur $15 \%$ of the time, while the latter set would occur $63 \%$ of the time. A set with a single transition would occur $21 \%$ of the time. A set of four transitions is possible, but the probability is only $0.5 \%$. As the atomic mass increases, the density of discrete states also tends to increase such that many transitions are possible for MeV-scale incident neutrons from a single inelastic scatter on medium- $Z$ to high- $Z$ isotopes. At sufficiently high excitation energies, the states form a continuum whose energies are unresolved or inaccessible experimentally. For sufficiently energetic incident neutrons, such as $14 \mathrm{MeV}$ neutrons from a D-T neutron generator, the probability to excite the nucleus to the continuum of states is high for most nuclei. Neutron capture follows a similar physical process with the exception that a new excited nucleus is formed from the neutron absorption. The possible sets of transitions to the ground state follow from the transition rules for the new nucleus.

\section{Radiation Transport Codes and ENDF Libraries}

This section describes how the commonly used radiation transport codes, MCNP6.2 and Geant4.10, use the ENDF libraries to model secondary gamma emissions.

Users of radiation transport codes have two core requirements in computational accuracy and speed. While the primary requirement is the predicted quantity should be as accurate as possible, the simulation is arguably useless if the computation time is impractical, especially if the user desires to change input parameters to explore a particular parameter space. A simple radiation transport model with secondary gamma emissions has the following basic steps:

1. Emit neutrons from a user-defined source.

2. Transport neutrons and gammas through a user-defined medium of materials.

a. Calculate the path to next interaction for each neutron or secondary particle using the total cross-sections for the materials.

b. Use the reaction cross-sections to determine which reaction occurred.

c. If the neutron scatters, calculate the change in direction and energy for the neutron.

d. If neutrons or gammas are emitted, use the reaction physics to determine the emission direction, energy, and number of particles for each neutron or gamma.

3. Tally all contributions of neutrons and/or gammas to user-defined detectors.

In this simple framework, the reaction cross-sections, number and types of secondary particles, and outgoing direction and energy of secondary particles ideally can be found for nuclei in the Evaluated Nuclear Data File (ENDF) libraries. These libraries use the ENDF- 6 format ${ }^{25}$, which is the most used data

${ }^{25}$ Cross Sections Evaluation Working Group. (2010, July). ENDF-6 Formats Manual (BNL-90365-2009 Rev.1). Upton, NY: Brookhaven National Laboratory. 
format for nuclear data ${ }^{26}$. Neutron reaction libraries include ENDF/B-VIII.0, BROND-3.1, CENDL-3.1, JEFF-3.3, JENDL-4.0u, and TENDL-2019. The ENDF-6 format prescribes the data blocks, or files (MF), for reaction data libraries. Each MF contains nuclear data for reactions denoted with the MT reaction nomenclature ${ }^{27}$. The MFs relevant to secondary gamma emissions from neutron inelastic scattering and neutron capture are shown in Table A-1. The MTs associated with neutron inelastic scattering and neutron capture are shown in Table A-2. The ENDF-6 format has space for the data associated with total inelastic scattering $(M T=4)$, the data for inelastic scattering for the $1^{\text {st }}$ to $40^{\text {th }}$ excited states $(M T=51-90)$, and the data for the continuum of states (MT=91). In addition to the data for radiative capture (MT=102), the ENDF-6 format also has space for data in instances where the residual nucleus is left in an excited state after neutron capture (MF=601-649,651-699,701-749,751-799,801-849).

Table A-1. Data block, or file (MF), descriptions in the ENDF-6 format. The MF relevant to secondary gamma emission are highlighted.

\begin{tabular}{l|l} 
MF & Description \\
\hline $\mathbf{1}$ & General information \\
\hline $\mathbf{2}$ & Resonance parameter data \\
\hline $\mathbf{3}$ & Reaction cross sections \\
$\mathbf{4}$ & Angular distributions for emitted particles \\
\hline $\mathbf{5}$ & Energy distributions for emitted particles \\
$\mathbf{6}$ & Energy-angle distributions for emitted particles \\
$\mathbf{7}$ & Thermal neutron scattering law data \\
\hline $\mathbf{8}$ & Radioactivity and fission-product yield data \\
\hline $\mathbf{9}$ & Multiplicities for radioactive nuclide production \\
\hline $\mathbf{1 0}$ & Cross sections for radioactive nuclide production \\
\hline $\mathbf{1 2}$ & Multiplicities for photon production \\
$\mathbf{1 3}$ & Cross sections for photon production \\
$\mathbf{1 4}$ & Angular distributions for photon production \\
$\mathbf{1 5}$ & Energy distributions for photon production \\
\hline $\mathbf{2 3 - 2 8}$ & Photoatomic data \\
\hline $\mathbf{3 0 - 4 0}$ & Covariances \\
\hline
\end{tabular}

Table A-2. Reaction identifiers (MT) relevant to secondary gamma emissions from neutron inelastic scattering and neutron capture.

\begin{tabular}{|l|l|}
$\mathbf{M T}$ & Description \\
\hline $\mathbf{1}$ & Total cross-section \\
\hline $\mathbf{3}$ & Total non-elastic cross-section (total minus elastic) \\
\hline $\mathbf{4}$ & Sum of MT=50-91 \\
\hline $\mathbf{5}$ & Sum of all reactions not given explicitly in another MT \\
\hline $\mathbf{5 1}$ & Inelastic scattering $\left(n, n^{\prime} \gamma\right)$, exciting the nucleus in the first excited state \\
\hline
\end{tabular}

\footnotetext{
${ }^{26}$ Koning, A. J., Rochman, D., Sublet, J.-C., Dzysiuk, N., Fleming, M., \& van der Marck, S. (2019). TENDL: Complete Nuclear Data Library for Innovative Nuclear Science and Technology. Nuclear Data Sheets, 155, 1-55.

https://doi.org/10.1016/j.nds.2019.01.002

27 See Appendix B of the BNL-90365-2009 Rev.1.
} 


\begin{tabular}{|l|l|}
\hline $\mathbf{M T}$ & Description \\
\hline $\mathbf{5 2}$ & $\left(n, n^{\prime} \gamma\right)$, exciting the nucleus in the second excited state \\
\hline $\mathbf{\ldots}$ & $\ldots$ \\
\hline $\mathbf{9 0}$ & $\left(n, n^{\prime} \gamma\right)$, exciting the nucleus in the $40^{\text {th }}$ excited state \\
\hline $\mathbf{9 1}$ & $\left(n, n^{\prime} \gamma\right)$, exciting the nucleus to the continuum of states \\
\hline $\mathbf{1 0 2}$ & Radiative capture $(n, \gamma)$ \\
\hline $\mathbf{6 0 1}$ & Neutron capture, producing a proton, exciting the nucleus to the first excited state \\
\hline $\mathbf{6 0 2}$ & $(n, p)$, exciting the nucleus to the second excited state \\
\hline$\ldots$ & $\ldots$ \\
\hline $\mathbf{6 4 9}$ & $(n, p)$, exciting the nucleus to the continuum of states \\
\hline $\mathbf{6 5 1}$ & Neutron capture, producing a deuteron, exciting the nucleus to first excited state \\
\hline $\mathbf{6 5 2}$ & $(n, d)$, exciting the nucleus to second excited state \\
\hline$\ldots$ & $\ldots$ \\
\hline $\mathbf{6 9 9}$ & $(n, d)$, exciting the nucleus to continuum of states \\
\hline $\mathbf{7 0 1}$ & Neutron capture, producing a triton, exciting the nucleus to first excited state \\
\hline $\mathbf{7 0 2}$ & $(n, t)$, exciting the nucleus to second excited state \\
\hline$\ldots$ & $\ldots$ \\
\hline $\mathbf{7 4 9}$ & $(n, t)$, exciting the nucleus to continuum of states \\
\hline $\mathbf{7 5 1}$ & Neutron capture, producing a ${ }^{3}$ He particle, exciting the nucleus to first excited state \\
\hline $\mathbf{7 5 2}$ & $\left(n,{ }^{3}\right.$ He $)$, exciting the nucleus to second excited state \\
\hline$\ldots$ & $\ldots$ \\
\hline $\mathbf{7 9 9}$ & $\left(n,{ }^{3}\right.$ He $)$, exciting the nucleus to continuum of states \\
\hline $\mathbf{8 0 1}$ & Neutron capture, producing an alpha, exciting the nucleus to first excited state \\
\hline $\mathbf{8 0 2}$ & $(n, \alpha)$, exciting the nucleus to second excited state \\
\hline$\ldots$ & $\ldots$ \\
\hline $\mathbf{8 4 9}$ & $(n, \alpha)$, exciting the nucleus to continuum of states \\
\hline & \\
\hline
\end{tabular}

The data availability for each isotope per the highlighted MFs in Table A-1 influences how well secondary gamma emissions for the various MTs in Table A-2 can be modeled. A data summary description for the highlighted MFs and list of notes are given in Table A-3. Using the information in Table A-3, the following outline recasts the previous steps under bullet 2 to model neutron inelastic scattering when exciting the nucleus to the discrete states:

2. Transport neutrons through a user-defined medium of materials

a. Calculate the path to next interaction for each neutron using the total cross-sections for the materials $(\mathrm{MF}=3, \mathrm{MT}=1)$.

b. Use the reaction cross-sections to determine which reaction occurred ( $M F=3, M T=a l l)$. Neutron undergoes inelastic scattering to one of the discrete states (MT=51-90).

c. Sample the outgoing energy and direction for the scattered neutron with either $\mathrm{MF}=4$ or $\mathrm{MF}=6$.

d. Sample the emitted gammas (number and energies) using $M F=6$ or $M F=12$. However, sampling from $M F=6$ violates energy and momentum conservation. 
This transport description applies to low MeV-scale neutron sources, such as D-D neutron generators (2.5 MeV), AmLi/AmBe sources, and fission neutron sources like ${ }^{252} \mathrm{Cf}$. $14 \mathrm{MeV}$ neutron sources (i.e., D-T neutron generators) are sufficiently energetic to excite most nuclei to the continuum with a non-trivial probability. For excitation to the continuum of states:

2. Transport neutrons through a user-defined medium of materials

a. Calculate the path to next interaction for each neutron using the total cross-sections for the materials ( $M F=3, M T=1)$.

b. Use the reaction cross-sections to determine which reaction occurred ( $M F=3, M T=a l l)$. Neutron undergoes inelastic scattering to the continuum (MT=91).

c. Sample the outgoing energy and direction for the scattered neutron with either $\mathrm{MF}=5$ or $\mathrm{MF}=6$ or a combination of $\mathrm{MF}=4$ and $\mathrm{MF}=5$. However, because the excitation energy is not known, energy and momentum are not conserved.

d. Sample the emitted gammas (number and energies) using $M F=12$ or the combination of $M F=6$ and $M F=15$. There is a modeling limitation due to the ENDF maximum of 40 excited states. Per ENSDF, there are nuclei with data beyond the $40^{\text {th }}$ excited state.

For instances where the $\mathrm{MF}=6$ or $\mathrm{MF}=12$ data are unavailable, the gamma multiplicity and spectrum may be sampled using the $\mathrm{MT}=3$ or $\mathrm{MT}=5$. $\mathrm{MT}=3$ may be used by nuclear data evaluators to include secondary particles that cannot be easily associated with another MT. The noted issues with sampling emitted gammas manifest primarily for User Group \#2 who depend upon accurate event-by-event modeling. These issues typically do not manifest for User Group \#1 who model average quantities, such as modeling of reactors and gamma spectrometry. Instead, discrepancies arising from modeling average quantities are caused by incomplete or inaccurate nuclear data. One method for addressing the incomplete secondary gamma emission data for users in User Group \#1 is to split the model into two parts. The first part consists of performing the neutron transport and calculating the spatial distribution of neutron interactions where gamma emission occurs. The second part consists of defining the gamma source based upon the interaction locations and transporting the gammas to the detectors ${ }^{28}$. This approach depends upon the accurate modeling of gamma emission. Though the focus was on inelastic scattering in the above transport example, candidate signatures that rely on cascades from neutron capture reactions would have similar issues. A summary of capabilities supported by the ENDF libraries are given in Table A-4.

\footnotetext{
${ }^{28}$ Alfonso, K., Elsalim, M., King, M., Strellis, D., \& Gozani, T. (2013). MCNP Simulation Benchmarks for a Portable Inspection System for Narcotics, Explosives, and Nuclear Material Detection. IEEE Transactions on Nuclear Science, 60(2), 520-527. https://doi.org/10.1109/tns.2012.2227801.
} 
Table A-3. Data description and notes for the MF relevant to secondary gamma emission. The most important notes are shown in bold typeface.

\begin{tabular}{|c|c|c|}
\hline MF & Data Summary Description & Notes \\
\hline 3 & $\begin{array}{l}\text { - Cross-sections tabulated vs. incident } \\
\text { neutron energy }\left(E_{n}\right)\end{array}$ & $\begin{array}{l}\text { - Used to determine the likelihood that a particular } \\
\text { reaction occurred when a neutron interacts } \\
\text { - Most isotopes have inelastic scattering cross- } \\
\text { section data for the first several excited states in } \\
\text { ENDF/B-VIII.0 } \\
\text { - Most isotopes (but fewer than the number in the } \\
\text { previous bullet) have inelastic scattering cross- } \\
\text { section data for excitation to the continuum in } \\
\text { ENDF/B-VIII.0 }\end{array}$ \\
\hline 6 & $\begin{array}{l}\text { - Yields of gammas }\left(v_{\gamma}\right) \text { are tabulated } \\
\text { vs. } E_{n} \\
\text { - Distributions of de-excitation photons } \\
\left(E_{\gamma}\right) \text { and angle }\left(\mu_{\gamma}\right) \text { vs. } E_{n}\end{array}$ & $\begin{array}{l}\text { - Impossible to unambiguously reconstruct a } \\
\text { gamma cascade from an excited state } \\
\text { - Energy conservation violated on an event-by- } \\
\text { event basis, but correct on average } \\
\text { - Many isotopes have their inelastic scattering } \\
\text { gamma emission data in this MF } \\
\text { - If MF=12 is populated in ENDF/B-VIII.0, MF=6 } \\
\text { should have no gamma yields }\end{array}$ \\
\hline 12 & $\begin{array}{l}\text { - Transition probabilities are given, } \\
\text { including internal conversion }(L O=2) \\
\text { OR } \\
\text { - Multiplicities are tabulated vs. } E_{n} \\
(L O=1)\end{array}$ & $\begin{array}{l}\text { - Probabilities of gamma emitted are given, so } \\
\text { cascades can be reconstructed by examining the } \\
\text { subsequent excited states } \\
\text { - } \mathrm{LO}=1 \text { option less common than } \mathrm{LO}=2 \\
\text { - If there are no } \mathrm{MF}=13 \text { data, } \mathrm{MF}=3 \text { data are } \\
\text { required to determine how often the reaction } \\
\text { occurs }\end{array}$ \\
\hline 13 & - Similar in structure to $\mathrm{MF}=12, \mathrm{LO}=1$ & $\begin{array}{l}\text { - Uncommon in current neutron libraries } \\
\text { - Appears most often for } \mathrm{MT}=3, \mathrm{MT}=4 \text {, and some } \\
\text { neutron capture reactions in ENDF/B-VIII.0 }\end{array}$ \\
\hline 14 & $\begin{array}{l}\text { - Direction cosine distributions } \\
\text { tabulated vs. } E_{n}\end{array}$ & $\begin{array}{l}\text { - Appears to be default isotropic for all isotopes } \\
\text { with } \mathrm{MF}=14 \text { data in ENDF/B-VIII.0 }\end{array}$ \\
\hline 15 & $\begin{array}{l}\text { - De-excitation photon energy spectra } \\
\text { with corresponding probabilities } \\
\text { tabulated vs. } E_{n}\end{array}$ & $\begin{array}{l}\text { - Impossible to unambiguously reconstruct a } \\
\text { gamma cascade from an excited state } \\
\text { - Energy conservation violated on an event-by- } \\
\text { event basis, but correct on average } \\
\text { - Appears most often for MT=3,16,18,22,28,91, } \\
\text { 102,103,107 in ENDF/B-VIII.0 }\end{array}$ \\
\hline
\end{tabular}


Table A-4. Ability for the ENDF libraries to support the needs of User Group \#1 and User Group \#2. The most important notes are shown in bold typeface.

\begin{tabular}{|c|c|c|}
\hline \multirow{2}{*}{ Quantity } & \multicolumn{2}{|c|}{ Ability for ENDF libraries to support: } \\
\hline & User Group \#1 & User Group \#2 \\
\hline Cross-sections & \multicolumn{2}{|c|}{$\begin{array}{l}\text { Compensating errors in the elastic/non-elastic data means that } \\
\text { data cannot be mixed between libraries }\end{array}$} \\
\hline \multicolumn{3}{|l|}{ Momentum conservation } \\
\hline \begin{tabular}{l|l} 
Scattered neutron \\
\end{tabular} & \multicolumn{2}{|c|}{ 2-body kinematics } \\
\hline \multicolumn{3}{|l|}{$\begin{array}{l}\text { Nucleus recoil (discrete } \\
\text { states) }\end{array}$} \\
\hline \multicolumn{3}{|l|}{ Nucleus recoil (continuum) } \\
\hline $\begin{array}{l}\text { Gamma spectrum (discrete and } \\
\text { continuum) }\end{array}$ & $\begin{array}{l}\text { Noted discrepancies between } \\
\text { experimental data and ENDF }\end{array}$ & \\
\hline Gamma cascades (discrete) & & $\begin{array}{l}\text { MF=12 data needs to be added } \\
\text { for many isotopes and } \\
\text { accessing data beyond the } 40^{\text {th }} \\
\text { excited state needs to be added }\end{array}$ \\
\hline Gamma cascades (continuum) & & Fundamental ENDF limitation \\
\hline Energy conservation for gammas & & $\begin{array}{l}\text { MF=12 data needs to be added } \\
\text { for many isotopes }\end{array}$ \\
\hline Non-elastic gammas (MT=3) & & $\begin{array}{l}\text { Not correlated to reactions but } \\
\text { potentially important }\end{array}$ \\
\hline \multirow[t]{2}{*}{ Color key: } & No improvements necessary & Could be improved \\
\hline & Significant work needed & Does not apply \\
\hline
\end{tabular}

The current limits of data availability in the ENDF libraries are evident in the secondary gamma emission models in Geant4 and MCNP6. For Geant4, NeutronHP (High Precision) and LEND (Low Energy Neutron Data) are options for performing neutron transport. NeutronHP uses data libraries, such as JEFF3.3, ENDF/B-VIII.0, BROND-3.1, and JENDL-4.0u, in the G4NDL format, and has two physics approaches to the neutron transport: (1) strict compliance to the data libraries and (2) adjust the libraries to conserve energy and momentum. In the former approach, the overall average quantities are preserved, but NeutronHP will inherit any energy and momentum violations in the data libraries, such as with MF=6 data. In the latter approach, adjusting the libraries requires the emission of artificial gammas to conserve energy and momentum. In contrast to NeutronHP, LEND interfaces with the Monte Carlo General Interaction Data Interface (MCGIDI) ${ }^{29}$, which samples cross-section, multiplicity distribution, and energy and angular distribution data from a legacy, unsupported version of the Generalized Nuclear Database Structure (GNDS) ${ }^{30}$. LEND would need to be updated to use the current version of MCGIDI to be compatible with new releases of data libraries in the GNDS.

\footnotetext{
${ }^{29}$ Beck, Bret, and USDOE National Nuclear Security Administration. General Interaction Data Interface. Computer software. https://www.osti.gov//servlets/purl/1542552. Vers. 3.17. USDOE National Nuclear Security Administration (NNSA). 11 Mar. 2019. Web. doi:10.11578/dc.20190715.7

${ }^{30}$ Mattoon, C. M., Beck, B. R., Patel, N. R., Summers, N. C., Hedstrom, G. W., \& Brown, D. A. (2012). Generalized Nuclear Data: A New Structure (with Supporting Infrastructure) for Handling Nuclear Data. Nuclear Data Sheets, 113(12), 3145-3171. https://doi.org/10.1016/j.nds.2012.11.008
} 
Overall Geant4 will accurately model inelastic scattering in almost all cases if the neutron interaction accesses only the discrete states and all gamma emission probabilities are available and accurate via the $\mathrm{MF}=12$ data. However, due to the limitations of the data libraries, Geant4 cannot accurately model gamma emissions from excitations to the continuum without the development of a new secondary gamma event generator that can quickly and accurately produce gammas as the nucleus de-excites from the continuum through the quasi-continuum and discrete states to the ground state. NeutronHP has the additional modeling deficiency related to breakup reactions. NeutronHP ignores all ENDF breakup reaction flags by default and is known to emit unphysical gammas during the de-excitation from high energy states for the reaction ${ }^{12} \mathrm{C}+n \rightarrow{ }^{12} \mathrm{C}^{*}+n^{\prime} \rightarrow n^{\prime}+3 \alpha$. A Geant4 flag can be turned on to enable correct modeling of the carbon breakup reaction, but this feature is a special case. A list of breakup reactions in the ENDF libraries is given in Table D-11 (see Appendix D). The gamma emissions from these reactions may not be modeled accurately.

MCNP6 uses the ENDF libraries in the ACE ${ }^{31}$ format to perform the neutron transport. In the current version of MCNP6 (MCNP6.2), gamma production is not correlated with the neutron reaction unless the Cascading Gamma-ray Multiplicity (CGM) code ${ }^{32}$ option is turned on by the user. CGM is based upon the Hauser-Feshbach statistical model and simulates the emitted gammas from all transitions to the ground state. This code has been shown to replicate good quality ENDF data and fill in missing ENDF data ${ }^{32}$ and can model excitations to the continuum of states $^{33}$. While the Hauser-Feshbach statistical model is an excellent approximation for energies above the resonance region, the model can only reproduce averaged cross-sections in the resonance region so that ENDF data must be used in this region. Low-Z nuclei typically have resonance regions that extend above $10 \mathrm{MeV}$, so the Hauser-Feshbach statistical model has limited utility for these nuclei in the energy ranges of interest for most users. MCNP6.2+CGM limits modeling of correlated emissions to nuclei with $Z>9$.

A recent Workshop for Applied Nuclear Data Activities (WANDA) 2020 presentation ${ }^{34}$ indicates that there are issues with the CGM implementation into MCNP6.2 that need to be addressed. One issue pertains to the calculation of the excitation energy that is used for particle emission. For the CGM implementation in MCNP6.1.1, the excitation energy was calculated with the correct Q-value for the reaction that was sampled. While other particles (e.g., neutrons) are not emitted directly using CGM, the energy and particle information was subtracted from the excitation energy so that the total energy of the gammas emitted did not exceed the Q-value. MCNP6.1.1+CGM is useful for modeling gamma emissions without the correlated neutrons. For the CGM implementation in MCNP6.2, neutrons and gammas are emitted using CGM, and an average neutron binding energy is used instead of the actual Qvalue for the reaction. Using a constant binding energy for all reactions results in the emitted particles not having the correct total energy for each reaction. The other issue pertains to the computational resource requirements for MCNP6.2+CGM. For a simple problem of $100 \mathrm{keV}$ neutrons colliding into gold, MCNP6.2+CGM is 1000 times slower than MCNP6.2 with the CGM option turned off ${ }^{35}$.

\footnotetext{
${ }^{31} \mathrm{ACE}=\mathrm{A}$ Compact ENDF

32 Wilcox, T., McKinney, G., \& Kawano, T. (2014, September). MCNP6 Gets Correlated with CGM 3.4 (LA-UR-1421300). Los Alamos, New Mexico: Los Alamos National Laboratory.

${ }^{33}$ Kawano, T., Talou, P., Chadwick, M., \& Watanabe, T. (2010). Monte Carlo Simulation for Particle and -Ray Emissions in Statistical Hauser-Feshbach Model. Journal of Nuclear Science and Technology, 47(5), 462-469. https://doi.org/10.1080/18811248.2010.9711637

${ }^{34}$ Rising, M. E. (2020, March). Event-by-Event Physics Modeling through Transport and Detector Response Simulations (LA-UR-20-21801). Los Alamos, NM: Los Alamos National Laboratory.

35 Personal communication with Michael Rising of Los Alamos National Laboratory.
} 
A summary of the MCNP6.2 and Geant4.10 capabilities for modeling secondary gamma emission is given in Table A-5.

Table A-5. Summary of the MCNP6.2 and Geant4.10 capabilities for modeling secondary gamma emissions. The most important notes are shown in bold typeface.

\begin{tabular}{|c|c|c|c|}
\hline \multirow[b]{2}{*}{ Quantity } & \multirow{2}{*}{$\begin{array}{l}\text { User Group \#1 } \\
\text { MCNP6.2 }\end{array}$} & \multicolumn{2}{|c|}{ User Group \#2 } \\
\hline & & MCNP6.2 & Geant4.10 \\
\hline Cross-sections & \multicolumn{3}{|c|}{$\begin{array}{l}\text { Compensating errors in the elastic/nonelastic data means that data } \\
\text { cannot be mixed between libraries }\end{array}$} \\
\hline \multicolumn{4}{|l|}{ Momentum conservation } \\
\hline Scattered neutron & \multicolumn{3}{|c|}{ 2-body kinematics } \\
\hline Nucleus recoil (discrete states) & & \multicolumn{2}{|l|}{ No recoil } \\
\hline Nucleus recoil (continuum) & & No recoil & $\begin{array}{l}\text { Limited by } \\
\text { ENDF data }\end{array}$ \\
\hline $\begin{array}{l}\text { Gamma spectrum (discrete and } \\
\text { continuum) }\end{array}$ & $\begin{array}{l}\text { Known discrepancies between } \\
\text { experimental data and ENDF (See } \\
\text { Appendix C) }\end{array}$ & & \\
\hline \multicolumn{2}{|l|}{ Gamma cascades (discrete) } & \multicolumn{2}{|c|}{$\begin{array}{l}\text { Limited by ENDF data (see Table } \\
\text { A-4) }\end{array}$} \\
\hline Gamma cascades (continuum) & & \multicolumn{2}{|c|}{$\begin{array}{l}\text { Significant effort needed for } \\
\text { modeling gammas emitted when } \\
\text { de-exciting from the continuum } \\
\text { to the ground state }\end{array}$} \\
\hline Energy conservation for gammas & & \multicolumn{2}{|c|}{$\begin{array}{l}\text { Limited by ENDF data (see Table } \\
\text { A-4) }\end{array}$} \\
\hline $\begin{array}{l}\text { Time correlation between scattered } \\
\text { neutron and emitted gammas }\end{array}$ & & \multicolumn{2}{|c|}{$\begin{array}{l}\text { Gammas not } \\
\text { correlated to } \\
\text { neutrons } \\
\text { without CGM }\end{array}$} \\
\hline $\begin{array}{l}\text { Energy correlation between scattered } \\
\text { neutron and emitted gammas }\end{array}$ & & $\begin{array}{l}\text { Gammas not } \\
\text { correlated to } \\
\text { neutrons } \\
\text { without CGN }\end{array}$ & $\begin{array}{l}\text { Limited by } \\
\text { ENDF data (see } \\
\text { Table A-4) }\end{array}$ \\
\hline Non-elastic gammas (MT=3) & & \multicolumn{2}{|c|}{$\begin{array}{l}\text { Limited by ENDF data (see Table } \\
\text { A-4) }\end{array}$} \\
\hline \multirow[t]{2}{*}{ Color key: } & No improvements necessary & \multirow{2}{*}{\multicolumn{2}{|c|}{$\begin{array}{l}\text { Could be improved } \\
\text { Does not apply }\end{array}$}} \\
\hline & Significant work needed & & \\
\hline
\end{tabular}

\section{Recommendations}

The nuclear data gaps and modeling shortfalls can be summarized as:

- Unavailability of MF=12 Multiplicities for Photon Production data for many isotopes or several states of an isotope. The status of the MF and MT data availability for several ENDF libraries is given in Appendix D. These data enable modeling of gamma cascades when exciting to the discrete states with low MeV-scale neutron sources. These data may also be used for an effort to develop an event generator that models the transitions from the continuum of states to the ground state. There are instances where the gamma emission probabilities are available in the ENSDF libraries but are not available in ENDF libraries. For example, the gamma emission probabilities for ${ }^{184} \mathrm{~W}\left(n, n^{\prime} \gamma\right)$ are available in ENSDF for up to the $43^{\text {rd }}$ excited state, but 
ENDF/B-VIII.0 only has cross-section data and gamma emission probability data for the $1^{\text {st }}$ through $6^{\text {th }}$ excited states. Follow-on work includes reconciling the gamma emission data in ENDF/B-VIII.0 with the data in ENSDF, such as by ensuring that all isotopes in Table 4 have $\mathrm{MF}=12$ data. However, this effort is limited by the availability of cross-section data for the reactions. A corollary effort could include establishing benchmark datasets to perform quality assurance checks on any improvements to ENDF/B libraries. One example is the Baghdad Atlas $^{36}$.

- Incomplete or inaccurate cross-section data for the reactions that result in secondary gamma emission. Some known instances of incomplete or inaccurate cross-section data are given in Appendix C. A complete assessment of the incomplete or inaccurate cross-section data was outside the scope of this study. Follow-on work includes an assessment of the inelastic scattering and neutron capture cross-section data spanning thermal energies to $14 \mathrm{MeV}$. There may be existing datasets that have not been considered for inclusion into ENDF/B. Checking existing data with new measurements may be feasible if a source and detector setup is already available.

- ENDF-6 format limitation of $\mathbf{4 0}$ excited states. For many medium-Z to high-Z nuclei, ENSDF contains gamma emission probability data beyond the $40^{\text {th }}$ excited state. For example, ENDF/BVIII.O has cross-section and gamma emission probability data for inelastic scattering to the first 40 excited states of ${ }^{56} \mathrm{Fe}$. However, ENSDF has gamma emission probabilities for the first 57 excited states. Follow-on work includes extending the GNDS to include the level density information and allow states to be embedded in the continuum. This effort will be needed for the development of a secondary gamma event generator.

- Inability to adequately model excitations to the continuum of states and de-excitations to the ground state. Follow-on work includes the development of a secondary gamma event generator that can model excitations to the continuum and de-excitations to the ground state. Such a model would be analogous to the Fission Reaction Event Yield Algorithm (FREYA) ${ }^{37}$. FREYA contains enough physics to accurately model correlated neutrons and gammas from fission while also being computationally practical. One option would be to update MCGIDI to incorporate an event generator based upon RAINIER ${ }^{38}$ and then update the Geant4 LEND option to use the new MCGIDI. CGM may also be a candidate once its current issues are resolved, and MCNP6+CGM is validated and demonstrated to be computationally practical.

Upon completion of the synchronization of the gamma data between ENSDF and ENDF/B-VIII.0 and the update to the GNDS to accommodate states beyond the $40^{\text {th }}$ excited state, the results would benefit from validation by modeling a simple experiment. If this validation is pursued before developing the

\footnotetext{
${ }^{36}$ Hurst, A. M., Bernstein, L. A., \& Chong, S. (2017, March). Compilation of the "Atlas of Gamma-rays from the Inelastic Scattering of Reactor Fast Neutrons" (1978DE41) by A.M. Demidov, L.I. Govor, Yu. K. Cherepantsev, M.R. Ahmed, S. Al-Najjar, M.A. Al-Amili, N. Al-Assafi, and N. Rammo (LBNL-1007259). Berkeley, CA: Lawrence Berkeley National Laboratory. https://doi.org/10.2172/1372676

${ }^{37}$ Vogt, R., \& Randrup, J. (2020). Detailed modeling of fission with FREYA. Nuclear Instruments and Methods in Physics Research Section A: Accelerators, Spectrometers, Detectors and Associated Equipment, 954, 161225. https://doi.org/10.1016/j.nima.2018.09.060.

${ }^{38}$ Kirsch, L. E., \& Bernstein, L. A. (2018). RAINIER: A simulation tool for distributions of excited nuclear states and cascade fluctuations. Nuclear Instruments and Methods in Physics Research Section A: Accelerators, Spectrometers, Detectors and Associated Equipment, 892, 30-40. https://doi.org/10.1016/j.nima.2018.02.096
} 
secondary gamma event generator, such a validation is possible using the Mercury ${ }^{39}$ code developed at Lawrence Livermore National Laboratory. Mercury performs neutron and gamma transport, supports a 3-D geometry definition, and uses the latest version of MCGIDI, which employs data in the latest GNDS version. Mercury cannot be considered a sufficient long-term alternative to MCNP6.2 and Geant4.10 currently because its usage is restricted to LLNL computing resources only.

${ }^{39}$ Brantley, P., Beck, B., Jurgenson, E., Ebbers, C., Hall, J., Dawson, S., McKinley, M., O’Brien, M., \& Stevens, D. (2013). Recent Advances in the Mercury Monte Carlo Particle Transport Code. Lawrence, CA: Lawrence Livermore National Laboratory. 


\section{APPENDIX B. References to Applications that Utilize Secondary Gamma Emissions}

This appendix contains a brief list of applications (see Table B-1) with references that utilize secondary gamma emissions. As material assay via secondary gamma emission analysis is a broad topic, the list of references is intended to provide a starting point for examining a particular application. An annex to this document contains information on additional applications.

Table B-1. Brief list of applications that utilize secondary gamma emissions. The list of references is intended to provide a starting point for examining a particular application.

\begin{tabular}{|c|c|}
\hline Application & 10 \\
\hline $\begin{array}{l}\text { Industrial } \\
\text { applications (e.g. } \\
\text { coal or mineral } \\
\text { analysis) }\end{array}$ & $\begin{array}{l}\text { Dep, L., Belbot, M., Vourvopoulos, G., \& Sudar, S. (1998). Pulsed neutron- } \\
\text { based on-line coal analysis. Journal of Radioanalytical and Nuclear Chemistry, } \\
\text { 234(1-2), 107-112. https://doi.org/10.1007/bf02389756 } \\
\text { - Lim, C. S., \& Abernethy, D. A. (2005). On-line coal analysis using fast neutron- } \\
\text { induced gamma-rays. Applied Radiation and Isotopes, 63(5-6), 697-704. } \\
\text { https://doi.org/10.1016/j.apradiso.2005.05.021 } \\
\text { - Gozani, T. (1994). Industrial applications of neutron physics methods (INIS- } \\
\text { mf--13907). Elias, E. (Ed.). Israel }\end{array}$ \\
\hline $\begin{array}{l}\text { Controlled } \\
\text { Substances } \\
\text { Detection (e.g., } \\
\text { chemical warfare } \\
\text { agents, } \\
\text { explosives, } \\
\text { narcotics) }\end{array}$ & $\begin{array}{l}\text { - Strellis, D., \& Gozani, T. (2005). Classifying threats with a 14-MeV neutron } \\
\text { interrogation system. Applied Radiation and Isotopes, 63(5-6), 799-803. } \\
\text { https://doi.org/10.1016/j.apradiso.2005.05.037 } \\
\text { - Twomey, T. R., Caffrey, A. J., \& Chichester, D. L. (2007, February). } \\
\text { Nondestructive Identification of Chemical Warfare Agents and Explosives by } \\
\text { Neutron Generator-Driven PGNAA (INL/CON-07-12304). Idaho National } \\
\text { Laboratory. https://inldigitallibrary.inl.gov/sites/sti/sti/3693723.pdf } \\
\text { - Sullivan, R. (2009, March). An Advanced ESTCP PELAN System for Surface and } \\
\text { Near-surface UXO Discrimination (MM-200503). Science Applications } \\
\text { International Corporation. } \\
\text { https://apps.dtic.mil/dtic/tr/fulltext/u2/a512848.pdf } \\
\text { Valkovic, V., Sudac, D., \& Matika, D. (2010). Fast neutron sensor for detection } \\
\text { of explosives and chemical warfare agents. Applied Radiation and Isotopes, } \\
\text { 68(4-5), 888-892. https://doi.org/10.1016/j.apradiso.2009.09.055 } \\
\text { - Strellis, D. A., Elsalim, M., \& Gozani, T. (2011). Explosives (and other threats) } \\
\text { detection using pulsed neutron interrogation and optimized detectors. } \\
\text { Detection and Sensing of Mines, Explosive Objects, and Obscured Targets } \\
\text { XVI, 1-6. https://doi.org/10.1117/12.884421 } \\
\text { Viesti, G. (2014). Status report on the detection of illicit materials in cargo } \\
\text { containers by using neutron beams. Proceedings of 10th Latin American }\end{array}$ \\
\hline
\end{tabular}




\begin{tabular}{|c|c|}
\hline Application & References \\
\hline & $\begin{array}{l}\text { Symposium on Nuclear Physics and Applications - PoS(X LASNPA), 1-10. } \\
\text { https://doi.org/10.22323/1.194.0002 } \\
\text { - Sardet, A., Pérot, B., Carasco, C., Sannié, G., Moretto, S., Nebbia, G., ... } \\
\text { Tintori, C. (2018). Gamma signatures of the C-BORD Tagged Neutron } \\
\text { Inspection System. EPJ Web of Conferences, 170, 07011. } \\
\text { https://doi.org/10.1051/epjconf/201817007011 } \\
\text { D. N. Vakhtin, I. Y. Gorshkov, A. V. Evsenin, and O. I. Osetrov, "SENNA - } \\
\text { Portable Sensor for Explosives Detection Based on Nanosecond Neutron } \\
\text { Analysis," in Detection and Disposal of Improvised Explosives (H. Schubert } \\
\text { and A. Kuznetsov, eds.), NATO }\end{array}$ \\
\hline Oil-well logging & $\begin{array}{l}\text { Mauborgne, M.-L., Allioli, F., Stoller, C., Evans, M., Manclossi, M., \& Nicoletti, } \\
\text { L. (2017). Exploring for oil with nuclear physics. EPJ Web of Conferences, 146, } \\
\text { 09009. https://doi.org/10.1051/epjconf/201714609009 } \\
\text { Mauborgne, M.-L., Allioli, F., Manclossi, M., Nicoletti, L., Stoller, C., \& Evans, } \\
\text { M. (2017). Designing tools for oil exploration using nuclear modeling. EPJ } \\
\text { Web of Conferences, 146, 09036. } \\
\text { https://doi.org/10.1051/epjconf/201714609036 }\end{array}$ \\
\hline Reactor design & $\begin{array}{l}\text { - Rimpault, G., Bernard, D., Blanchet, D., Vaglio-Gaudard, C., Ravaux, S., \& } \\
\text { Santamarina, A. (2012). Needs of Accurate Prompt and Delayed p-spectrum } \\
\text { and Multiplicity for Nuclear Reactor Designs. Physics Procedia, 31, 3-12. } \\
\text { https://doi.org/10.1016/j.phpro.2012.04.002 } \\
\text { - Lemaire, M., Vaglio-Gaudard, C., Lyoussi, A., \& Reynard-Carette, C. (2015). } \\
\text { For a better estimation of gamma heating in nuclear material-testing } \\
\text { reactors and associated devices: status and work plan from calculation } \\
\text { methods to nuclear data. Journal of Nuclear Science and Technology, 52(9), } \\
\text { 1093-1101. https://doi.org/10.1080/00223131.2015.1009957 } \\
\text { Zerkle, M. (2020, April 3). NNL Transport Code - MC21 [Slides]. LBL } \\
\text { Conferences (INDICO). https://conferences.Ibl.gov/event/292/ }\end{array}$ \\
\hline Space exploration & $\begin{array}{l}\text { - Trombka, J. I., Starr, R. D., Groves, J., Akkurt, H., Evans, L. G., McCoy, T. J., } \\
\text { Parsons, A. M., Schweitzer, J., Amatucci, E., Smith, M. T., Floyd, S., \& } \\
\text { McClanahan, T. P. (2005). A pulsed neutron gamma-ray system for Mars } \\
\text { rover missions. } 2005 \text { IEEE Aerospace Conference, 1-10. } \\
\text { https://doi.org/10.1109/aero.2005.1559358 } \\
\text { Parsons, A., Bodnarik, J., Evans, L., Floyd, S., Lim, L., McClanahan, T., } \\
\text { Namkung, M., Nowicki, S., Schweitzer, J., Starr, R., \& Trombka, J. (2011). } \\
\text { Active neutron and gamma-ray instrumentation for in situ planetary science } \\
\text { applications. Nuclear Instruments and Methods in Physics Research Section }\end{array}$ \\
\hline
\end{tabular}




\begin{tabular}{|c|c|}
\hline Application & References \\
\hline & $\begin{array}{l}\text { A: Accelerators, Spectrometers, Detectors and Associated Equipment, } \\
652(1), 674-679 . \text { https://doi.org/10.1016/j.nima.2010.09.157 } \\
\text { Wilson, J. T., Lawrence, D. J., Peplowski, P. N., \& Feldman, W. C. (2019). } \\
\text { MESSENGER Gamma Ray Spectrometer and Epithermal Neutron Hydrogen } \\
\text { Data Reveal Compositional Differences Between Mercury's Hot and Cold } \\
\text { Poles. Journal of Geophysical Research: Planets, 124(3), 721-733. } \\
\text { https://doi.org/10.1029/2018je005871 } \\
\text { Ayllon Unzueta, M. (2020, March 4). From earth to outer space: surface } \\
\text { composition analysis with neutron-induced gamma rays [Slides]. LBL } \\
\text { Conferences (INDICO). https://conferences.Ibl.gov/event/292/ }\end{array}$ \\
\hline $\begin{array}{l}\text { Nuclear material } \\
\text { analysis using } \\
\text { gamma-ray } \\
\text { fission products }{ }^{40}\end{array}$ & $\begin{array}{l}\text { - Chernikova, D., Axell, K., Avdic, S., Pázsit, I., Nordlund, A., \& Allard, S. (2015). } \\
\text { The neutron-gamma Feynman variance to mean approach: Gamma } \\
\text { detection and total neutron-gamma detection (theory and practice). Nuclear } \\
\text { Instruments and Methods in Physics Research Section A: Accelerators, } \\
\text { Spectrometers, Detectors and Associated Equipment, 782, 47-55. } \\
\text { https://doi.org/10.1016/j.nima.2015.01.104 } \\
\text { - S. Kane, T. Gozani, M. J. King, J. Kwong, C. Brown, C. Gary, M. I. Firestone, J. } \\
\text { a. Nikkel, and D. N. McKinsey, "Simulations of Multi-Gamma Coincidences } \\
\text { From Neutron-Induced Fission in Special Nuclear Materials," IEEE } \\
\text { Transactions on Nuclear Science, vol. 60, pp. 533-538, Apr. 2013. } \\
\text { K. S. Kim, L. F. Nakae, M. K. Prasad, N. J. Snyderman \& J. M. Verbeke (2017) } \\
\text { Fission Chain Restart Theory, Nuclear Science and Engineering, 188:1, 57-84, } \\
\text { DOI: 10.1080/00295639.2017.1340691 } \\
\text { Enqvist, A., Pozzi, S. a., Flaska, M., \& Pázsit, I. (2010). Initial evaluation for a } \\
\text { combined neutron and gamma ray multiplicity counter. Nuclear Instruments } \\
\text { and Methods in Physics Research Section A: Accelerators, Spectrometers, } \\
\text { Detectors and Associated Equipment, 621(1-3), 493-497. } \\
\text { https://doi.org/10.1016/j.nima.2010.06.226 }\end{array}$ \\
\hline
\end{tabular}

${ }^{40}$ Cascades of gammas from non-fission reactions constitute a background for correlated fission observables. 


\section{APPENDIX C. Examples of Measurement Data and Modeling Discrepancies}

This appendix contains examples of measurement data and modeling discrepancies for User Group \#1 and User Group \#2.

For User Group \#1, the researchers in the oil-well logging industry have described instances of inaccurate or incomplete nuclear data via measurement data and modeling discrepancies ${ }^{41}$. From measurements with $14 \mathrm{MeV}$ neutron sources, Marie-Laure Mauborgne of Schlumberger provided the assessment shown in Table C-1. Ed Seabury of Idaho National Laboratory noted nuclear data issues with nitrogen, sulfur, titanium, and arsenic ${ }^{42}$. Using MCNP6 and ENDF/B-VII, measurements of the $2.3 \mathrm{MeV}$ signature for nitrogen can only be modeled to within an order magnitude. For sulfur, inelastic scattering produces gammas with the wrong energies and there are no apparent capture gamma emissions. Similar measurement data and modeling discrepancies have been observed for titanium and arsenic. Benchmark comparisons by users are uncommon or challenging to find in the literature. To adequately evaluate existing cross-section data, a comprehensive nuclear data expert and user effort to assess the elements in Table 4 would be helpful for confirming the experimental priorities.

Table C-1. An assessment of the modeled and measured gamma spectra agreement for the oil-well logging industry ${ }^{43}$.

\begin{tabular}{|c|c|c|}
\hline Element & Capture & Inelastic scattering \\
\hline \multicolumn{3}{|l|}{$\mathbf{H}$} \\
\hline \multicolumn{3}{|l|}{ C } \\
\hline \multicolumn{3}{|l|}{0} \\
\hline $\mathrm{Na}$ & $\begin{array}{l}\text { Improvements noticeable in ENDF/B-VII } \\
\text { and newer }\end{array}$ & $\begin{array}{l}\text { Peak energy resolution is very broad, but } \\
\text { otherwise no noticeable change in cross- } \\
\text { section data across the ENDF/B libraries }\end{array}$ \\
\hline Mg & $\begin{array}{l}\text { Gamma emission data in ENDF/B-VII and } \\
\text { newer have lower resolution and high- } \\
\text { energy signatures are missing }\end{array}$ & $\begin{array}{l}\text { Improvements noticeable in ENDF/B-VII } \\
\text { and newer, but the signature at } 1.81 \mathrm{MeV} \\
\text { is missing }\end{array}$ \\
\hline Al & $\begin{array}{l}\text { Improvements noticeable in ENDF/B-VII } \\
\text { and newer }\end{array}$ & \\
\hline Si & Apparent discrepancies above $7 \mathrm{MeV}$ & $\begin{array}{l}\text { Strongest gamma signatures are good, but } \\
\text { the measured spectrum is too low above } \\
1.77 \mathrm{MeV} \text {, suggesting an issue with the } \\
\text { continuum data }\end{array}$ \\
\hline \multicolumn{3}{|r|}{ 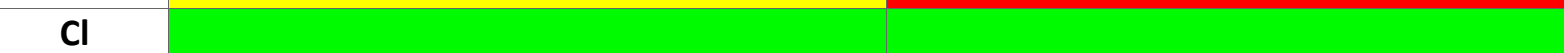 } \\
\hline $\mathrm{Ca}$ & $\begin{array}{l}\text { Significant degradation in data for ENDF/B- } \\
\text { VII and newer }\end{array}$ & $\begin{array}{l}\text { Improvements noticeable in ENDF/B-VII } \\
\text { and newer }\end{array}$ \\
\hline $\mathrm{Ti}$ & $\begin{array}{l}\text { Significant degradation in data for ENDF/B- } \\
\text { VII and newer }\end{array}$ & $\begin{array}{l}\text { Improvements noticeable in ENDF/B-VII } \\
\text { and newer }\end{array}$ \\
\hline
\end{tabular}

\footnotetext{
${ }^{41}$ Mauborgne, M.-L., Radtke, R. J., Stoller, C., \& Haranger, F. (2020). Impact of the ENDF/B-VIII.0 library on modeling nuclear tools for oil exploration. EPJ Web of Conferences, 239, 20007.

https://doi.org/10.1051/epjconf/202023920007

${ }^{42}$ Personal communication with Ed Seabury of Idaho National Laboratory.

${ }^{43}$ Personal communication with Marie-Laure Mauborgne of Schlumberger.
} 


\begin{tabular}{|c|c|c|}
\hline Element & Capture & Inelastic scattering \\
\hline Mn & $\begin{array}{l}\text { Improvements made }{ }^{44} \text {, but unclear } \\
\text { whether they are widely available }\end{array}$ & $\begin{array}{l}\text { Minor discrepancies apparent with } \\
\text { differences in ENDF/B releases }\end{array}$ \\
\hline $\mathrm{Fe}$ & $\begin{array}{l}\text { Significant degradation data in ENDF/B- } \\
\text { VIII.0 with several signatures missing } \\
\text { between } 2 \mathrm{MeV} \text { and } 5 \mathrm{MeV} \text { and the } 9.3 \\
\text { MeV signature missing }\end{array}$ & $\begin{array}{l}\text { Agreement appears best below } 2 \mathrm{MeV} \text { and } \\
\text { worst above } 5 \mathrm{MeV}\end{array}$ \\
\hline \multirow[t]{2}{*}{ Color key: } & No improvements necessary & Could be improved \\
\hline & Significant work needed & Does not apply \\
\hline
\end{tabular}

For User Group \#2, an example of a measurement data and modeling discrepancy was provided by one of the authors. The measurement involved the material characterization of three annuli using an associated particle imaging (API) D-T neutron generator and an array of pixelated plastic scintillator (EJ200) detectors ${ }^{45}$. The primary objective of this measurement was to demonstrate material characterization by reconstructing the location of elastic scatter events. The scatter angle distribution and the relationship between the scatter angles and arrival times depend upon the atomic mass. Elastic scatter event reconstruction is well-suited to low-Z material identification. As the detectors are sensitive to both neutrons and gammas via time-of-flight, an inelastic scatter reconstruction capability may enable a general method for material characterization spanning low- $Z$ to high-Z materials in transmission reconstructions. Thus, the gamma-neutron correlations to alpha events were analyzed as a secondary objective.

The key data structure in the measurement is the time distribution of events (i.e., time-of-flight) following an alpha event in the neutron generator's alpha detector. The time-of-flight distribution contains features that correspond to:

1. A peak with induced gammas from the copper heat sink next to the neutron generator target and the steel wall of the neutron generator accelerator tube;

2. A peak with induced gammas from the object under interrogation;

3. A peak with transmitted $14 \mathrm{MeV}$ neutrons and small-angle elastic scatter neutrons; and

4. A broad peak with:

a. Induced fission or $(n, x n)$ neutrons, large-angle elastic scatter neutrons, inelastic scatter neutrons from the object and

b. Scattered neutrons and induced gammas from interactions in the detector array.

A typical time distribution is shown in Figure C-1.

\footnotetext{
${ }^{44}$ Capote, R., Smith, D. L., Trkov, A., \& Meghzifene, M. (2012). A New Formulation of the Unified Monte Carlo Approach (UMC-B) and Cross-Section Evaluation for the Dosimetry Reaction $55 \mathrm{Mn}(\mathrm{n}, \gamma) 56 \mathrm{Mn}$. Journal of ASTM International, 9(3), 104115. https://doi.org/10.1520/jai104115.

${ }^{45}$ Blackston, M. A., \& Hausladen, P. A. (2015). Fast-neutron elastic-scatter imaging for material characterization. 2015 IEEE Nuclear Science Symposium and Medical Imaging Conference (NSS/MIC), 1-9.

https://doi.org/10.1109/nssmic.2015.7581846
} 


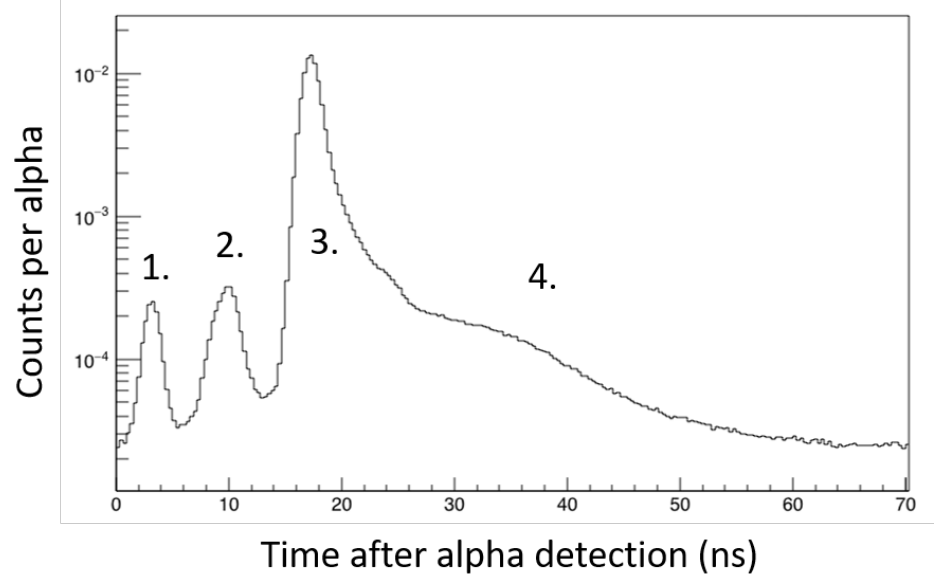

Figure C-1. Time distribution of events after alpha detection. A description of the numbered features can be found in the text.

In the measurement example, three annuli were placed next to each other in the alpha detector field-ofview. The annuli were composed of high-density polyethylene (HDPE), steel, or tungsten clad in a steel can, as shown in Figure C-2. The time-of-flight distribution was modeled in Geant4 and compared to the measured time-of-flight distribution. After matching the modeled detector response for neutrons as closely as possible to the measured detector response, the time-of-flight feature corresponding to induced gammas for each annulus were compared between model and measurement. As shown in Figure C-3, there are noticeable discrepancies for the HDPE and tungsten annuli. The model overpredicts the total induced gammas for the HDPE annulus by $22 \%$ and unpredicts the total induced gammas for the steel and tungsten annuli by $8 \%$ and $23 \%$, respectively. A comparison of model and measurement was performed for the gamma-neutron correlations associated with alpha events. For these correlations, the modeled and measured neutron time-of-flight distributions and the modeled and measured gamma energy spectra were compared, respectively. As shown in Figure C-4 and Figure C-5, though there were not many gamma-neutron correlations, the model consistently underestimates the number of gamma-neutron correlations for all three annuli despite the agreement to within $25 \%$ for the total induced gammas. While more work is needed to fully understand the detector response to gammas, these results indicate the need to improve the modeling of correlations on an event-by-event basis. 

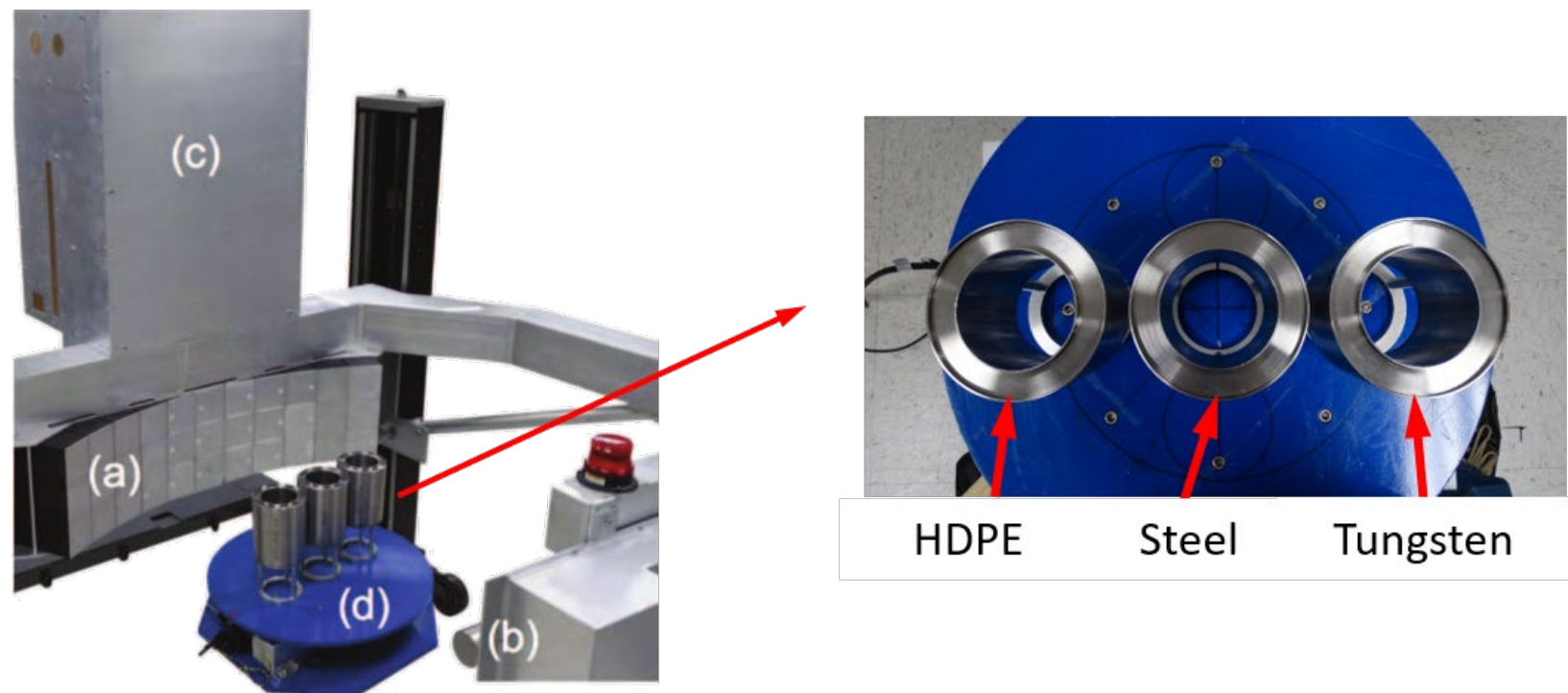

Figure C-2. (a) Pixelated plastic scintillator (EJ-200) array, (b) API D-T neutron generator, (c) data acquisition enclosure, and (d) arrangement HDPE, steel, and tungsten annuli.

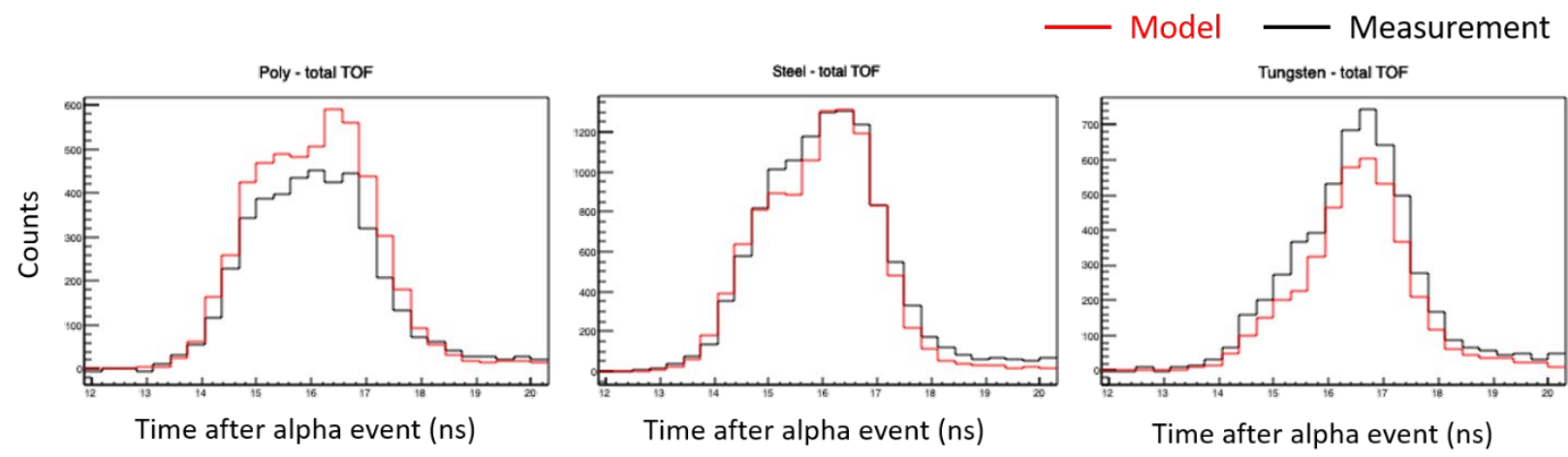

Figure C-3. Feature corresponding to total induced gammas for the (left) HDPE annulus, (middle) steel annulus, and (right) tungsten annulus.
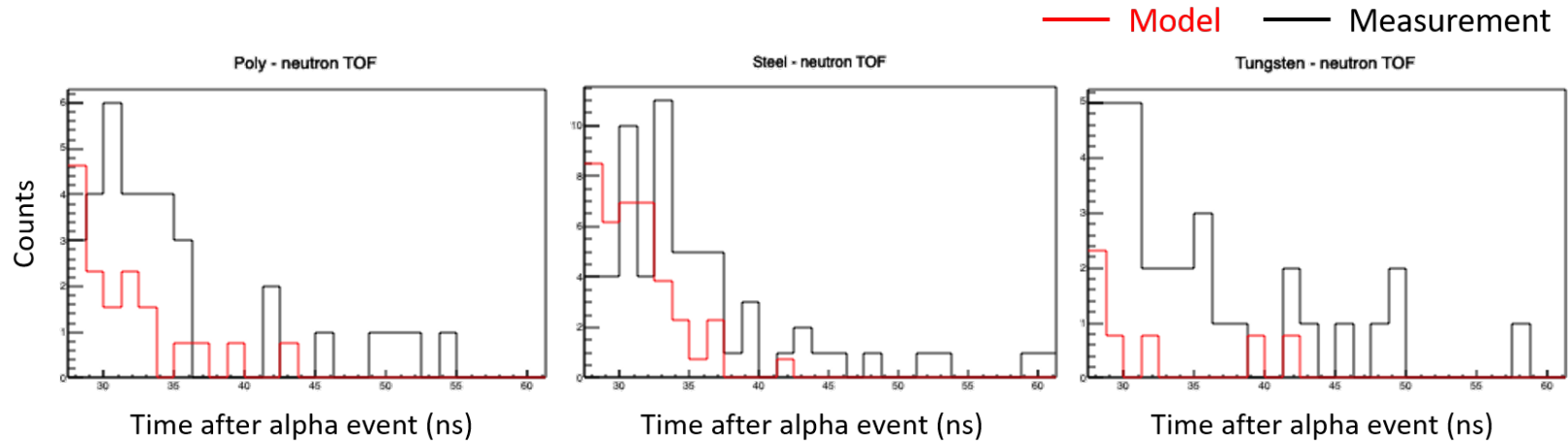

Figure C-4. Neutron time-of-flight distribution for gamma-neutron correlations associated with an alpha event for the (left) HDPE annulus, (middle) steel annulus, and (right) tungsten annulus. 

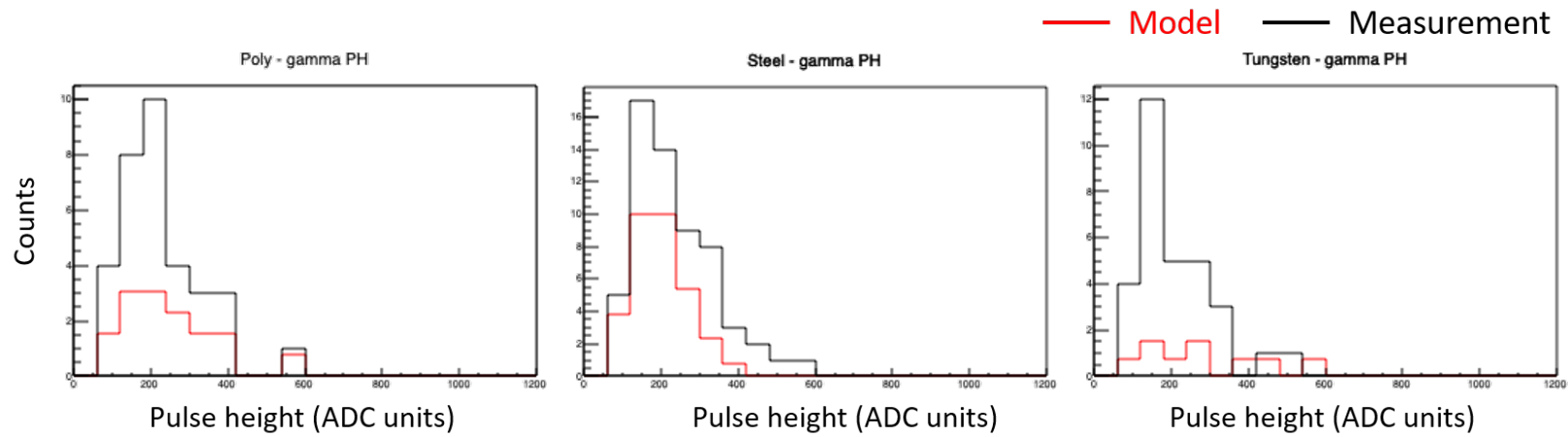

Figure C-5. Gamma pulse height spectra for the gamma-neutron correlations associated with an alpha event for the (left) HDPE annulus, (middle) steel annulus, and (right) tungsten annulus. 


\section{APPENDIX D. Availability of Secondary Gamma Emission Data in ENDF Libraries}

This appendix contains the results of a data discovery effort to assess the availability of secondary gamma emission data in the ENDF libraries listed in Table D-1. For each element listed in Table 4, the libraries were parsed to determine what MT are available for each MF listed in Table A-3. Then the parsed results were examined for the availability of MF=6 (energy-angle distributions for emitted particles) and MF=12 (multiplicities for photon production) data for inelastic scattering to the lower excited states for each isotope, e.g., MT=51-60. These data indicate gaps in MF=12 data that can be addressed for User Group \#2. The results of this effort for the priority elements are given in Table D-2, Table D-3, and Table D-4. The information used to generate the ENDF/B-VIII.0 column in Table D-2, Table D-3, and Table D-4 is given in Table D-5, Table D-6, and Table D-7, respectively. As the TENDL-2019 library is considered the most complete, its available data are given in Table D-8, Table D-9, and Table D10. For Table D-5 through Table D-10, the blue shaded cells in the natural abundance column indicate isotopes greater than $1 \%$ abundant. The orange shaded cells in the $\mathrm{MF}=6$ column indicate the existence of data for $M T=51$. The green shaded cells in the $M F=12$ column indicated the existence of data for $M T=51$. The natural abundances were sourced from the National Institutes of Standards and Technology ${ }^{46}$.

As noted in Appendix A, Geant4 ignores the ENDF breakup reaction flag by default. The carbon breakup reaction can be modeled as a special case by turning on a Geant4 flag, but there are other breakup reactions in the ENDF libraries for which the gamma emissions may not be modeled correctly. A list of breakup reactions in the ENDF libraries is given in Table D-11. All these isotopes are included in the priority element list of Table 4.

Follow-on efforts would include examining the quality of the existing $M F=12$ data, filling in the missing $\mathrm{MF}=12$ data, and examining the quality of the cross-section data (MF=3). Overall, the results of this discovery effort represent a starting point for comprehensively assessing the quality of the existing data. For example, non-elastic reactions other than inelastic scattering that can leave the residual nucleus in an excited state may be useful to examine at $14 \mathrm{MeV}$. Libraries formatted in GNDS were not evaluated during this effort. GNDS-formatted libraries are assumed to not contain significantly more secondary gamma emission information than the ENDF-6 formatted libraries.

${ }^{46}$ Coursey, J.S., Schwab, D.J., Tsai, J.J., and Dragoset, R.A. (2015), Atomic Weights and Isotopic Compositions (version 4.1). [Online] Available: http://physics.nist.gov/Comp [2020, October 15]. National Institute of Standards and Technology, Gaithersburg, MD. 
Table D-1. ENDF libraries evaluated for the availability of secondary gamma emission data.

\begin{tabular}{|c|c|}
\hline ENDF library & \\
\hline ENDF/B-VIII.0 & $\begin{array}{l}\text { Brown, D. A., Chadwick, M. B., Capote, R., Kahler, A. C., Trkov, A., Herman, M. W., } \\
\text { Sonzogni, A. A., Danon, Y., Carlson, A. D., Dunn, M., Smith, D. L., Hale, G. M., } \\
\text { Arbanas, G., Arcilla, R., Bates, C. R., Beck, B., Becker, B., Brown, F., Casperson, R. J., ... } \\
\text { Zhu, Y. (2018). ENDF/B-VIII.0: The 8th Major Release of the Nuclear Reaction Data } \\
\text { Library with CIELO-project Cross Sections, New Standards and Thermal Scattering } \\
\text { Data. Nuclear Data Sheets, 148, 1-142. https://doi.org/10.1016/j.nds.2018.02.001 }\end{array}$ \\
\hline BROND-3.1 & $\begin{array}{l}\text { Blokhin, A. I., Gai, E. V., Ignatyuk, A. V., Koba, I. I., Manokhin, V. N., \& Pronyaev, V. G. } \\
\text { (2016). NEW VERSION OF NEUTRON EVALUATED DATA LIBRARY BROND-3.1. } \\
\text { Problems of Atomic Science and Technology. Series: Nuclear and Reactor Constants, } \\
\text { 2, 62-93. https://vant.ippe.ru/en/year2016/2/neutron-constants/1150-5.html }\end{array}$ \\
\hline CENDL-3.1 & $\begin{array}{l}\text { Ge, Z. G., Zhao, Z. X., Xia, H. H., Zhuang, Y. X., Liu, T. J., Zhang, J. S., \& Wu, H. C. } \\
\text { (2011). The Updated Version of Chinese Evaluated Nuclear Data Library (CENDL-3.1). } \\
\text { Journal of the Korean Physical Society, 59(2(3)), 1052-1056. } \\
\text { https://doi.org/10.3938/jkps.59.1052 }\end{array}$ \\
\hline JEFF-3.3 & $\begin{array}{l}\text { Plompen, A. J. M., Cabellos, O., De Saint Jean, C., Fleming, M., Algora, A., Angelone, } \\
\text { M., Archier, P., Bauge, E., Bersillon, O., Blokhin, A., Cantargi, F., Chebboubi, A., Diez, } \\
\text { C., Duarte, H., Dupont, E., Dyrda, J., Erasmus, B., Fiorito, L., Fischer, U., ... Žerovnik, G. } \\
\text { (2020). The joint evaluated fission and fusion nuclear data library, JEFF-3.3. The } \\
\text { European Physical Journal A, 56(7), 1-108. https://doi.org/10.1140/epja/s10050- } \\
\text { 020-00141-9 }\end{array}$ \\
\hline JENDL-4.0 & $\begin{array}{l}\text { SHIBATA, K., IWAMOTO, O., NAKAGAWA, T., IWAMOTO, N., ICHIHARA, A., KUNIEDA, } \\
\text { S., CHIBA, S., FURUTAKA, K., OTUKA, N., OHSAWA, T., MURATA, T., MATSUNOBU, H., } \\
\text { ZUKERAN, A., KAMADA, S., \& KATAKURA, J.-. (2011). JENDL-4.0: A New Library for } \\
\text { Nuclear Science and Engineering. Journal of Nuclear Science and Technology, 48(1), } \\
\text { 1-30. https://doi.org/10.1080/18811248.2011.9711675 }\end{array}$ \\
\hline TENDL-2019 & $\begin{array}{l}\text { Koning, A. J., Rochman, D., Sublet, J.-C., Dzysiuk, N., Fleming, M., \& van der Marck, S. } \\
\text { (2019). TENDL: Complete Nuclear Data Library for Innovative Nuclear Science and } \\
\text { Technology. Nuclear Data Sheets, 155, 1-55. } \\
\text { https://doi.org/10.1016/j.nds.2019.01.002 }\end{array}$ \\
\hline
\end{tabular}


Table D-2. Data discovery results for inelastic scattering to the low excited states for the tier 1 elements.

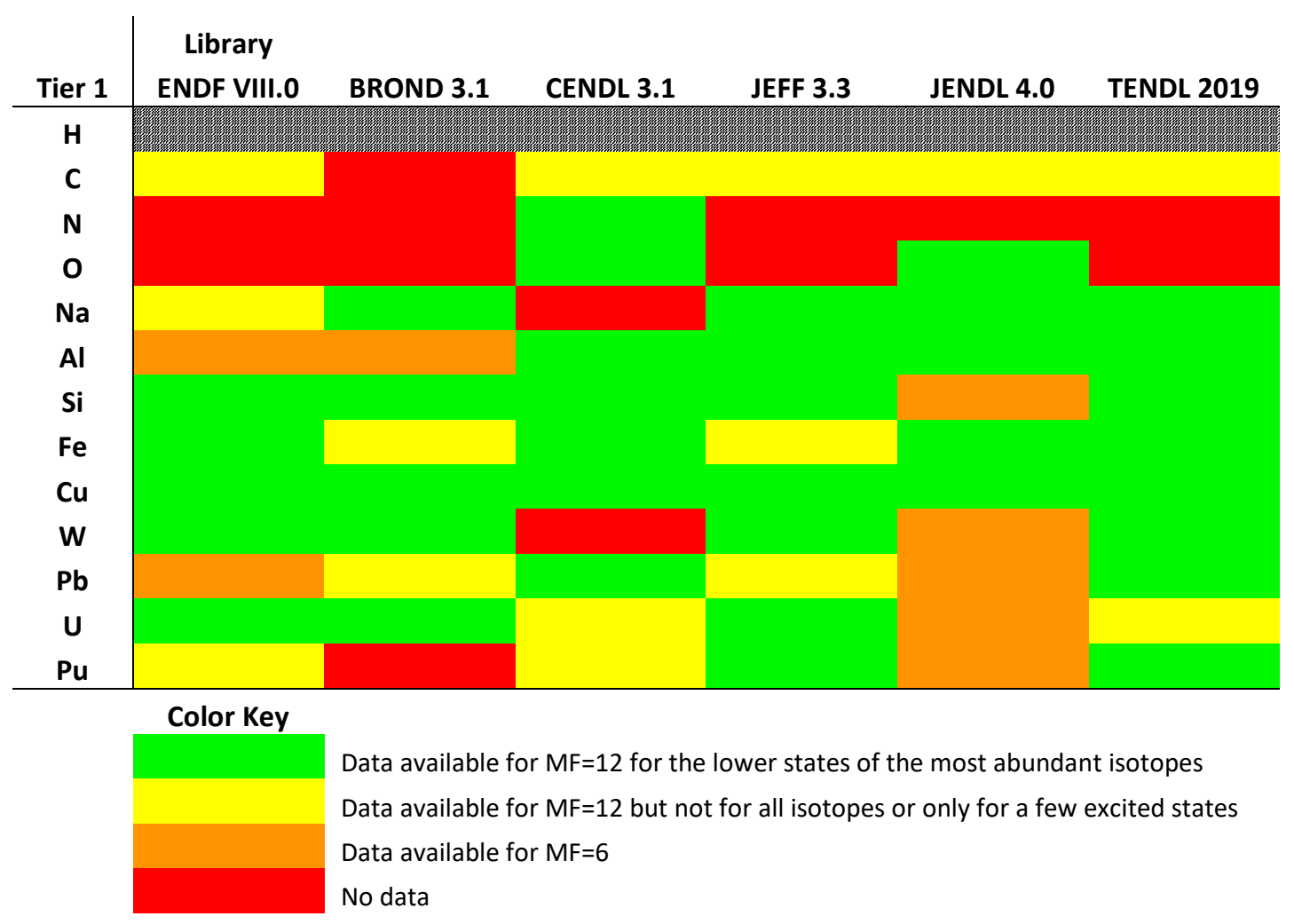


Table D-3. Data discovery results for inelastic scattering to the low excited states for the tier $\mathbf{2}$ elements.

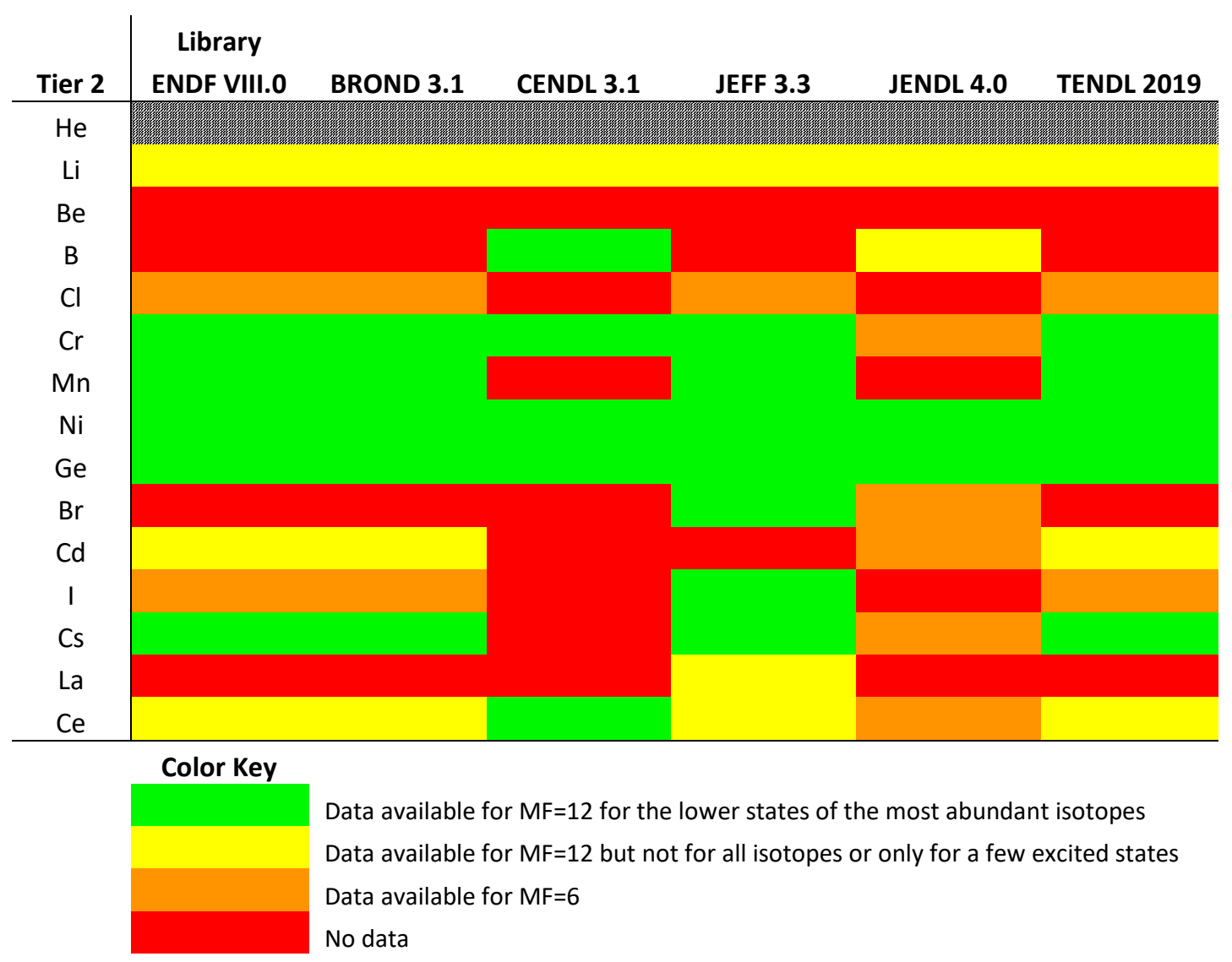


Table D-4. Data discovery results for inelastic scattering to the low excited states for the tier 3 elements.

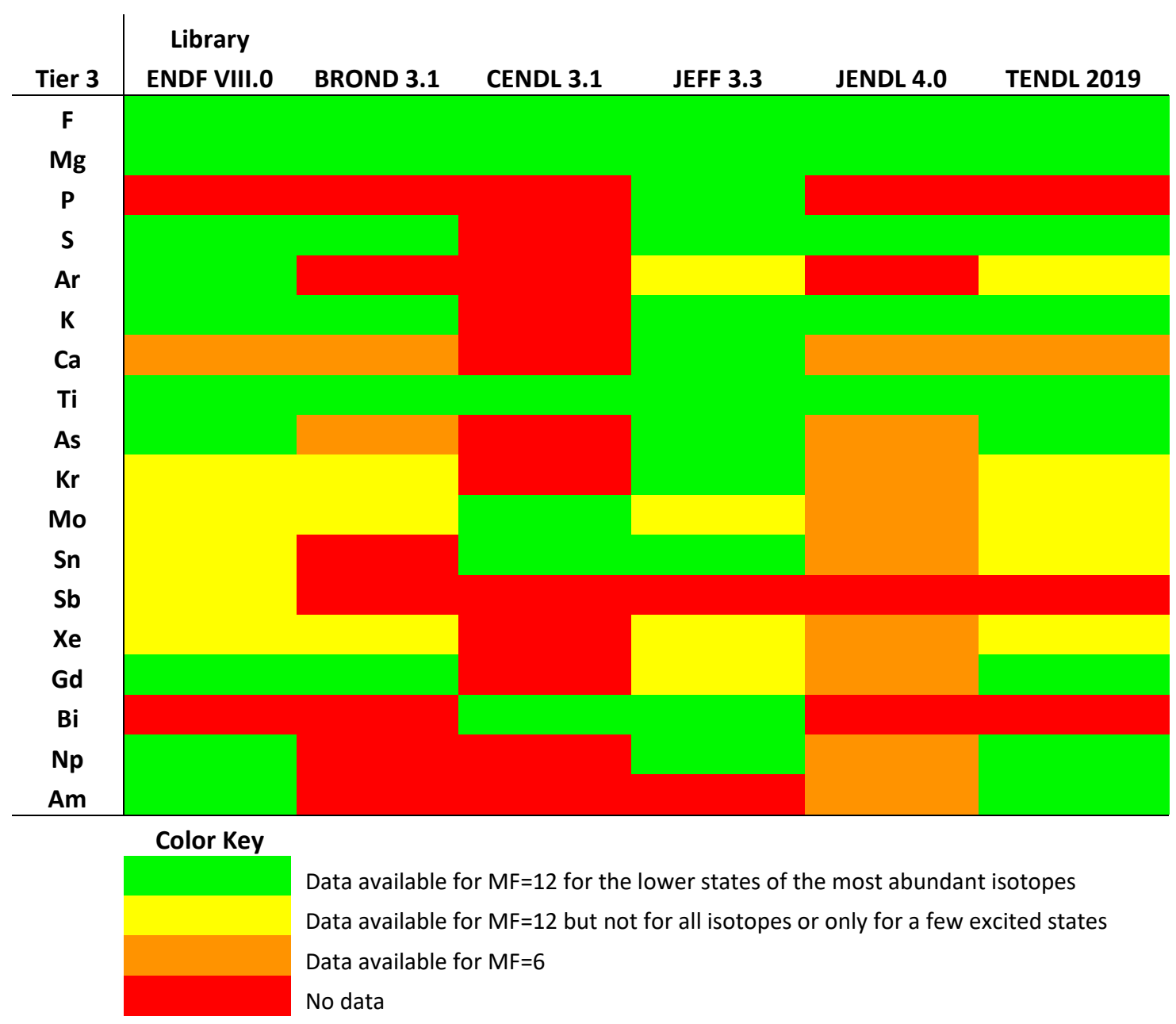


Table D-5. List of available MTs for MF=3, MF=6, and MF=12 in ENDF/B-VIII.0 for the tier 1 priority elements.

\begin{tabular}{|c|c|c|c|c|c|}
\hline \multicolumn{6}{|l|}{ Tier 1} \\
\hline Element & Symbol & $\begin{array}{c}\text { Natural } \\
\text { Abundance }\end{array}$ & $M F=3$ & $\mathrm{MF}=6$ & $\mathrm{MF}=12$ \\
\hline $\mathrm{H}$ & $\mathrm{H}-1$ & 0.9998857 & 1,102 & 102 & \\
\hline $\mathrm{C}$ & $\mathrm{C}-12$ & 0.98938 & $1,3-5,51-62,91,102$ & 5 & 51,102 \\
\hline $\mathrm{N}$ & $\mathrm{N}-14$ & 0.996362 & $\begin{array}{l}\text { 1, 4-5, 51-77, 102, 601-606, 651-653, } \\
701,801-810\end{array}$ & 5 & 102 \\
\hline 0 & $0-16$ & 0.9975716 & $\begin{array}{l}1,4-5,51-57,91,102,601-603,651- \\
669,701-709,749,801-803\end{array}$ & $5,91,749$ & 102 \\
\hline $\mathrm{Na}$ & $\mathrm{Na}-23$ & 1 & $1,3-4,51-68,91,102$ & & 51,102 \\
\hline Al & Al-27 & 1 & $\begin{array}{l}\text { 1, 3-5, 51-89, 91, 102, 601-619, 649, } \\
651-669,699,701-710,749,801-819, \\
849\end{array}$ & $\begin{array}{l}5,51-89,91,601-619,649,651-669, \\
699,701-710,749,801-819,849\end{array}$ & 102 \\
\hline \multirow[t]{3}{*}{$\mathrm{Si}$} & $\mathrm{Si}-28$ & 0.9222319 & $\begin{array}{l}\text { 1, 3-5, 51-67, 91, 102, 601-613, 649, } \\
801-815,849\end{array}$ & $\begin{array}{l}5,51-67,91,601-613,649,801-815 \\
849\end{array}$ & $51-67,102,601-613,801-815$ \\
\hline & Si-29 & 0.046858 & $\begin{array}{l}\text { 1, 3-5, 51-64, 91, 102, 601-615, 649, } \\
801-819,849\end{array}$ & $\begin{array}{l}5,51-64,91,601-615,649,801-819, \\
849\end{array}$ & $51-64,102,601-615,801-819$ \\
\hline & Si-30 & 0.0309211 & $\begin{array}{l}\text { 1, 3-5, 51-56, 91, 102, 601-605, 649, } \\
801-811,849\end{array}$ & $\begin{array}{l}\text { 5, 51-56, 91, 601-605, 649, 801-811, } \\
849\end{array}$ & $51-56,102,601-605,801-811$ \\
\hline \multirow[t]{4}{*}{$\mathrm{Fe}$} & Fe-54 & 0.0584535 & $\begin{array}{l}\text { 1, 4-5, 51-60, 91, 102, 601-633, 649, } \\
801-823\end{array}$ & $5,91,102,649$ & $51-60,601-633,801-823$ \\
\hline & Fe-56 & 0.9175436 & $\begin{array}{l}\text { 1, 4-5, 51-89, 91, 102, 601-609, 649, } \\
801-818\end{array}$ & $5,91,102,649$ & $51-89,601-609,801-818$ \\
\hline & Fe-57 & 0.021191 & $\begin{array}{l}\text { 1, 4-5, 51-64, 91, 102, 601-617, 649, } \\
801-838\end{array}$ & $5,91,102,649$ & $51-64,601-617,801-838$ \\
\hline & Fe-58 & 0.002824 & $\begin{array}{l}\text { 1, 3-5, 51-89, 91, 102, 601-616, 649, } \\
801-809\end{array}$ & $5,91,102,649$ & $51-89,601-616,801-809$ \\
\hline \multirow[t]{2}{*}{$\mathrm{Cu}$} & Cu-63 & 0.691515 & $1,3-5,51-79,91,102$ & $5,51-79,91,102$ & $51-79$ \\
\hline & Cu-65 & 0.308515 & $1,3-5,51-88,91,102$ & $5,51-88,91,102$ & $51-88$ \\
\hline
\end{tabular}




\begin{tabular}{|c|c|c|c|c|c|}
\hline Element & Symbol & $\begin{array}{c}\text { Natural } \\
\text { Abundance }\end{array}$ & $M F=3$ & $\mathrm{MF}=6$ & $M F=12$ \\
\hline \multirow[t]{5}{*}{ W } & W-180 & 0.00121 & $\begin{array}{l}1,4-5,51-58,91,102,601-614,649 \\
801-814,849\end{array}$ & $5,91,102,649,849$ & $51-58,601-614,801-814$ \\
\hline & W-182 & 0.265016 & $\begin{array}{l}1,4-5,51-59,91,102,601-629,649 \\
801-806,849\end{array}$ & $5,91,102,649,849$ & $51-59,601-629,801-806$ \\
\hline & W-183 & 0.14314 & $\begin{array}{l}1,4-5,51-61,91,102,601-614,649 \\
801-824,849\end{array}$ & $5,91,102,649,849$ & $51-61,601-614,801-824$ \\
\hline & W-184 & 0.30642 & $\begin{array}{l}1,4-5,51-56,91,102,649,801-807, \\
849\end{array}$ & $5,91,102,649,849$ & $51-56,801-807$ \\
\hline & W-186 & 0.284319 & $1,4-5,51-61,91,102,649,849$ & $5,91,102,649,849$ & $51-61$ \\
\hline \multirow[t]{4}{*}{$\mathrm{Pb}$} & $\mathrm{Pb}-204$ & 0.0141 & $\begin{array}{l}1,3-5,51-71,91,102,601-610,649 \\
651-655,699,701-705,749,751-753 \\
799,801-810,849\end{array}$ & $\begin{array}{l}5,51-71,91,102,601-610,649,651- \\
655,699,701-705,749,751-753,799 \\
801-810,849\end{array}$ & \\
\hline & $\mathrm{Pb}-206$ & 0.2411 & $\begin{array}{l}1,3-5,51-75,91,102,601-610,649, \\
651-655,699,701-705,749,801-810, \\
849\end{array}$ & $\begin{array}{l}5,51-75,91,102,601-610,649,651- \\
655,699,701-705,749,801-810,849\end{array}$ & \\
\hline & $\mathrm{Pb}-207$ & 0.2211 & $\begin{array}{l}1,3-5,51-70,91,102,601-610,649 \\
651-655,699,701-705,749,801-810 \\
849\end{array}$ & $\begin{array}{l}5,51-70,91,102,601-610,649,651- \\
655,699,701-705,749,801-810,849\end{array}$ & \\
\hline & $\mathrm{Pb}-208$ & 0.5241 & $\begin{array}{l}1,3-5,51-91,102,601-607,649,651- \\
666,699,701-723,749,801-807,849\end{array}$ & $\begin{array}{l}\text { 5, 51-91, 601-607, 649, 651-666, 699, } \\
701-723,749,801-807,849\end{array}$ & 102 \\
\hline \multirow[t]{2}{*}{$u$} & U-235 & 0.0072046 & $1,4-5,51-89,91,102,649,801-835$ & $5,91,102,649$ & $51-89,801-835$ \\
\hline & $\mathrm{U}-238$ & 0.9927421 & $1,4-5,51-89,91,102,649$ & $5,91,102,649$ & 51-89 \\
\hline \multirow[t]{2}{*}{$\mathrm{Pu}$} & Pu-239 & 0 & $1,3-4,51-91,102$ & 91,102 & $51-68$ \\
\hline & Pu-240 & 0 & $1,3-4,51-91,102$ & 91 & 4, 102 \\
\hline
\end{tabular}


Table D-6. List of available MTs for MF=3, MF=6, and MF=12 in ENDF/B-VIII.0 for the tier 2 priority elements.

\begin{tabular}{|c|c|c|c|c|c|}
\hline Element & Symbol & $\begin{array}{c}\text { Natural } \\
\text { Abundance }\end{array}$ & $\mathrm{MF}=3$ & $M F=6$ & $\mathrm{MF}=12$ \\
\hline \multirow[t]{2}{*}{$\mathrm{He}$} & $\mathrm{He}-3$ & 0.000001343 & 1,102 & & \\
\hline & $\mathrm{He}-4$ & 0.999998663 & 1 & & \\
\hline \multirow[t]{2}{*}{ Li } & Li-6 & 0.07594 & $1,4,51-81,102$ & & 57,102 \\
\hline & $\mathrm{Li}-7$ & 0.92414 & $1,4,51-82,102$ & & 51,102 \\
\hline $\mathrm{Be}$ & Be-9 & 1 & $1,3,102,701$ & 701 & 102 \\
\hline \multirow[t]{2}{*}{ B } & B-10 & 0.1997 & $1,3-4,51-85,102,601-605,801$ & 801 & 102 \\
\hline & B-11 & 0.8017 & $1,4,51-60,91,102$ & 91 & 102 \\
\hline \multirow[t]{2}{*}{$\mathrm{Cl}$} & $\mathrm{Cl}-35$ & 0.75761 & $\begin{array}{l}1,3-4,51-80,91,102,601-629,649, \\
651-680,699,701-730,749,801-820 \\
849\end{array}$ & $\begin{array}{l}51-80,91,601-629,649,651-680,699 \\
701-730,749,801-820,849\end{array}$ & 102 \\
\hline & $\mathrm{Cl}-37$ & 0.24241 & $\begin{array}{l}1,3-4,51-77,91,102,649,651-661 \\
699,701-715,749,801-805,849\end{array}$ & $\begin{array}{l}\text { 51-77, 91, 649, 651-661, 699, 701-715, } \\
749,801-805,849\end{array}$ & 102 \\
\hline \multirow[t]{4}{*}{$\mathrm{Cr}$} & $\mathrm{Cr}-50$ & 0.0434513 & $1,3-5,51-56,91,102$ & $5,51-56,91$ & $51-56,102$ \\
\hline & Cr-52 & 0.8378918 & $1,3-5,51-60,91,102$ & $5,51-60,91$ & $51-60,102$ \\
\hline & $\mathrm{Cr}-53$ & 0.0950117 & $1,3-5,51-63,91,102$ & $5,51-63,91$ & $51-63,102$ \\
\hline & $\mathrm{Cr}-54$ & 0.023657 & $1,3-5,51-54,91,102$ & $5,51-54,91$ & $51-54,102$ \\
\hline $\mathrm{Mn}$ & $\mathrm{Mn}-55$ & 1 & $\begin{array}{l}1,4-5,51-89,91,102,601-632,649, \\
801-831\end{array}$ & $5,91,102,649$ & $51-89,601-632,801-831$ \\
\hline \multirow[t]{5}{*}{$\mathrm{Ni}$} & $\mathrm{Ni}-58$ & 0.6807719 & $1,4-5,51-84,91,102$ & $5,51-84,91,102$ & $51-84$ \\
\hline & $\mathrm{Ni}-60$ & 0.2622315 & $1,4-5,51-79,91,102$ & $5,51-79,91,102$ & $51-79$ \\
\hline & $\mathrm{Ni}-61$ & 0.01139913 & $1,4-5,51-85,91,102$ & $5,51-85,91,102$ & $51-85$ \\
\hline & $\mathrm{Ni}-62$ & 0.0363464 & $1,4-5,51-88,91,102$ & $5,51-88,91,102$ & $51-88$ \\
\hline & $\mathrm{Ni}-64$ & 0.00925519 & $1,4-5,51-88,91,102$ & $5,51-88,91,102$ & $51-88$ \\
\hline Ge & Ge-70 & 0.205727 & $\begin{array}{l}1,4,51-89,91,102,601-619,649,801- \\
839,849\end{array}$ & $91,102,649,849$ & $51-89,601-619,801-839$ \\
\hline
\end{tabular}




\begin{tabular}{|c|c|c|c|c|c|}
\hline Element & Symbol & $\begin{array}{c}\text { Natural } \\
\text { Abundance }\end{array}$ & $M F=3$ & $\mathrm{MF}=6$ & $\mathrm{MF}=12$ \\
\hline & Ge-72 & 0.274532 & $\begin{array}{l}1,4,51-83,91,102,601-614,649,801- \\
827,849\end{array}$ & $91,102,649,849$ & $51-83,601-614,801-827$ \\
\hline & Ge-73 & 0.077512 & $\begin{array}{l}1,4,51-86,91,102,601-622,649,801- \\
837,849\end{array}$ & $91,102,649,849$ & $51-86,601-622,801-837$ \\
\hline & Ge-74 & 0.36502 & $1,4,51-89,91,102,649,801-804,849$ & $91,102,649,849$ & $51-89,801-804$ \\
\hline & Ge-76 & 0.077312 & $1,4,51-89,91,102,601-608,649,849$ & $91,102,649,849$ & $51-89,601-608$ \\
\hline \multirow[t]{2}{*}{$\mathrm{Br}$} & $\mathrm{Br}-79$ & 0.50697 & $1,4,51-79,91,102$ & & \\
\hline & $\mathrm{Br}-81$ & 0.49317 & $1,4,51-76,91,102$ & & \\
\hline \multirow[t]{8}{*}{$\mathrm{Cd}$} & Cd-106 & 0.01256 & $1,4,51-61,91,102$ & & $51-61,91,102$ \\
\hline & Cd-108 & 0.00893 & $1,4,51-60,91,102$ & & \\
\hline & $\mathrm{Cd}-110$ & 0.124918 & $1,4,51-64,91,102$ & & \\
\hline & Cd-111 & 0.128012 & $1,4,51-61,91,102$ & & $51-61,91,102$ \\
\hline & Cd-112 & 0.241321 & $1,4,51-58,91,102$ & & \\
\hline & Cd-113 & 0.122212 & $1,3-4,51-71,91,102$ & & \\
\hline & Cd-114 & 0.287342 & $1,4,51-60,91,102$ & & \\
\hline & Cd-116 & 0.074918 & $1,4,51-56,91,102$ & & \\
\hline $\mathrm{I}$ & $\mathrm{I}-127$ & 1 & $\begin{array}{l}1,4,51-71,91,102,601-622,649,801, \\
849\end{array}$ & $51-71,91,601-622,649,801,849$ & 102 \\
\hline Cs & Cs-133 & 1 & $\begin{array}{l}1,4,51-64,91,102,601-606,649,801- \\
814,849\end{array}$ & $91,102,649,849$ & $51-64,601-606,801-814$ \\
\hline \multirow[t]{2}{*}{ La } & La-138 & 0.000888171 & $1,4,51-65,91,102$ & & \\
\hline & La-139 & 0.999111971 & $1,4,51-61,91,102$ & & \\
\hline \multirow[t]{4}{*}{$\mathrm{Ce}$} & Ce-136 & 0.001852 & $\begin{array}{l}1,4,51-56,91,102,601-608,649,801- \\
811,849\end{array}$ & $91,102,649,849$ & $51-56,601-608,801-811$ \\
\hline & Ce-138 & 0.002512 & $\begin{array}{l}1,4,51-64,91,102,601-610,649,801- \\
810,849\end{array}$ & $91,102,649,849$ & $51-64,601-610,801-810$ \\
\hline & Ce-140 & 0.8845051 & $1,4,51-73,91,102$ & & \\
\hline & Ce-142 & 0.1111451 & $1,4,51-59,91,102$ & & \\
\hline
\end{tabular}


Table D-7. List of available MTs for MF=3, MF=6, and MF=12 in ENDF/B-VIII.0 for the tier 3 priority elements.

\begin{tabular}{|c|c|c|c|c|c|}
\hline Element & Symbol & $\begin{array}{c}\text { Natural } \\
\text { Abundance }\end{array}$ & $\mathrm{MF}=3$ & $M F=6$ & $\mathrm{MF}=12$ \\
\hline $\mathrm{F}$ & F-19 & 1 & $1,3-4,51-71,91,102$ & 91 & $51-71,102$ \\
\hline \multirow[t]{3}{*}{$\mathrm{Mg}$} & $M g-24$ & 0.78994 & $1,4,51-61,91,102$ & & $51-61,91,102$ \\
\hline & $\mathrm{Mg}-25$ & 0.10001 & $1,4,51-67,91,102$ & & $51-67,91,102$ \\
\hline & $\mathrm{Mg}-26$ & 0.11013 & $1,4,51-63,91,102$ & & $51-63,91,102$ \\
\hline $\mathrm{P}$ & P-31 & 1 & $1,4-5,91,102$ & 5 & 102 \\
\hline \multirow[t]{4}{*}{ S } & S-32 & 0.949926 & $1,4,51-56,91,102$ & & $51-56,91,102$ \\
\hline & S-33 & 0.00752 & $1,4,51-57,91,102$ & & $51-57,91,102$ \\
\hline & S-34 & 0.042524 & $1,4,51-55,91,102$ & & $51-55,91,102$ \\
\hline & S-36 & 0.00011 & $1,4,51-55,91,102$ & & $51-55,91,102$ \\
\hline \multirow[t]{3}{*}{$\mathrm{Ar}$} & Ar-36 & 0.00333621 & $1,4,51-71,91,102$ & & \\
\hline & Ar-38 & 0.0006297 & $1,4,51-69,91,102$ & & \\
\hline & Ar-40 & 0.99603525 & $1,4,51-68,91,102$ & $51-68,91,102$ & $51-68$ \\
\hline \multirow[t]{3}{*}{ K } & K-39 & 0.93258144 & $1,4,51-54,91,102$ & & $51-54,91,102$ \\
\hline & $\mathrm{K}-40$ & 0.0001171 & $1,4,51-55,91,102$ & & $51-55,91,102$ \\
\hline & $\mathrm{K}-41$ & 0.06730244 & $1,4,51-52,91,102$ & & $51-52,91,102$ \\
\hline \multirow[t]{3}{*}{$\mathrm{Ca}$} & Ca-40 & 0.96941156 & $\begin{array}{l}1,3-5,51-70,91,102,601-610,649 \\
651-655,699,701-705,749,751-755 \\
799,801-810,849\end{array}$ & $\begin{array}{l}\text { 5, 51-70, 91, 102, 601-610, 649, 651- } \\
655,699,701-705,749,751-755,799 \\
801-810,849\end{array}$ & \\
\hline & Ca-42 & 0.0064723 & $\begin{array}{l}1,3-5,51-70,91,102,601-610,649, \\
651-655,699,701-705,749,751-755, \\
799,801-810,849\end{array}$ & $\begin{array}{l}\text { 5, 51-70, 91, 102, 601-610, 649, 651- } \\
655,699,701-705,749,751-755,799 \\
801-810,849\end{array}$ & \\
\hline & Ca-43 & 0.001351 & $\begin{array}{l}1,3-5,51-70,91,102,601-610,649, \\
651-655,699,701-705,749,751-755, \\
799,801-810,849\end{array}$ & $\begin{array}{l}5,51-70,91,102,601-610,649,651- \\
655,699,701-705,749,751-755,799 \\
801-810,849\end{array}$ & \\
\hline
\end{tabular}




\begin{tabular}{|c|c|c|c|c|c|}
\hline Element & Symbol & $\begin{array}{c}\text { Natural } \\
\text { Abundance }\end{array}$ & $\mathrm{MF}=3$ & $\mathrm{MF}=6$ & $\mathrm{MF}=12$ \\
\hline & Ca-44 & 0.0208611 & $\begin{array}{l}1,3-5,51-70,91,102,601-610,649 \\
651-655,699,701-705,749,751-752 \\
801-810,849\end{array}$ & $\begin{array}{l}5,51-70,91,102,601-610,649,651- \\
655,699,701-705,749,751-752,801- \\
810,849\end{array}$ & \\
\hline & Ca-46 & 0.000043 & $\begin{array}{l}1,3-5,51-70,91,102,601-610,649, \\
651-655,699,701-705,749,801-804, \\
849\end{array}$ & $\begin{array}{l}5,51-70,91,102,601-610,649,651- \\
655,699,701-705,749,801-804,849\end{array}$ & \\
\hline & Ca-48 & 0.0018721 & $\begin{array}{l}1,3-5,51-70,91,102,601-604,649 \\
651-655,699,701-705,749,801-803 \\
849\end{array}$ & $\begin{array}{l}5,51-70,91,102,601-604,649,651- \\
655,699,701-705,749,801-803,849\end{array}$ & \\
\hline \multirow[t]{5}{*}{$\mathrm{Ti}$} & Ti-46 & 0.08253 & $1,4,51-59,91,102$ & 91,102 & $51-59$ \\
\hline & Ti-47 & 0.07442 & $1,4,51-66,91,102$ & 91,102 & $51-66$ \\
\hline & Ti-48 & 0.73723 & $1,4,51-68,91,102$ & 91,102 & $51-68$ \\
\hline & Ti-49 & 0.05412 & $1,4,51-65,91,102$ & 91,102 & $51-65$ \\
\hline & Ti-50 & 0.05182 & $1,4,51-61,91,102$ & 91,102 & $51-61$ \\
\hline As & As-75 & 1 & $\begin{array}{l}1,4,51-80,91,102,601-624,649,801- \\
809,849\end{array}$ & $91,102,649,849$ & $51-80,601-624,801-809$ \\
\hline \multirow[t]{6}{*}{$\mathrm{Kr}$} & $\mathrm{Kr}-78$ & 0.003553 & $1,4,51-61,91,102$ & $51-61,91,102$ & $51-61$ \\
\hline & $\mathrm{Kr}-80$ & 0.022861 & $1,4,51-79,91,102$ & & \\
\hline & $\mathrm{Kr}-82$ & 0.1159331 & $1,4,51-64,91,102$ & & \\
\hline & $\mathrm{Kr}-83$ & 0.1150019 & $1,4,51-65,91,102$ & & \\
\hline & $\mathrm{Kr}-84$ & 0.5698715 & $1,4,51-66,91,102$ & & \\
\hline & $\mathrm{Kr}-86$ & 0.1727941 & $1,4,51-60,91,102$ & & \\
\hline \multirow[t]{6}{*}{ Mo } & Mo-92 & 0.14533 & $1,4,51-66,91,102$ & 91 & 102 \\
\hline & Mo-94 & 0.09159 & $1,4,51-69,91,102$ & 91 & 102 \\
\hline & Mo-95 & 0.158411 & $1,4,51-78,91,102,601-639,649$ & $91,102,649$ & $51-78,601-639$ \\
\hline & Mo-96 & 0.166715 & $1,4,51-67,91,102$ & 91 & 102 \\
\hline & Mo-97 & 0.096014 & $1,4,51-63,91,102$ & 91 & 102 \\
\hline & Mo-98 & 0.243937 & $1,4,51-64,91,102$ & 91 & 102 \\
\hline
\end{tabular}




\begin{tabular}{|c|c|c|c|c|c|}
\hline $\begin{array}{c}\text { Tier } 3 \\
\text { Element }\end{array}$ & Symbol & $\begin{array}{c}\text { Natural } \\
\text { Abundance }\end{array}$ & $M F=3$ & $M F=6$ & $\mathrm{MF}=12$ \\
\hline & Mo-100 & 0.098231 & $1,4,51-57,91,102$ & & \\
\hline \multirow[t]{10}{*}{ Sn } & Sn-112 & 0.00971 & $1,4,51-73,91,102$ & & \\
\hline & Sn-114 & 0.00661 & $1,4,51-76,91,102$ & & \\
\hline & Sn-115 & 0.00341 & $1,4,51-66,91,102$ & & \\
\hline & Sn-116 & 0.14549 & $1,4,51-60,91,102$ & & \\
\hline & Sn-117 & 0.07687 & $1,4,51-62,91,102$ & & \\
\hline & Sn-118 & 0.24229 & $1,4,51-57,91,102$ & & \\
\hline & Sn-119 & 0.08594 & $1,4,51-70,91,102$ & & \\
\hline & Sn-120 & 0.32589 & $1,4,51-79,91,102$ & $51-79,91,102$ & $51-79$ \\
\hline & Sn-122 & 0.04633 & $1,4,51-59,91,102$ & & \\
\hline & Sn-124 & 0.05795 & $1,4,51-70,91,102$ & & \\
\hline \multirow[t]{2}{*}{$\mathrm{Sb}$} & Sb-121 & 0.57215 & $1,3-4,51-58,91,102$ & & \\
\hline & Sb-123 & 0.42795 & $1,3-4,51-56,91,102$ & & \\
\hline \multirow[t]{9}{*}{ Xe } & Xe-124 & 0.0009523 & $1,4,51-59,91,102$ & $51-59,91,102$ & $51-59$ \\
\hline & Xe-126 & 0.0008902 & $1,4,51-65,91,102$ & & \\
\hline & Xe-128 & 0.0191028 & $1,4,51-73,91,102$ & & \\
\hline & Xe-129 & 0.26400682 & $1,4,51-66,91,102$ & & \\
\hline & Xe-130 & 0.04071013 & $1,4,51-56,91,102$ & & \\
\hline & Xe-131 & 0.2123243 & $\begin{array}{l}1,4,51-65,91,102,601-614,649,801- \\
814,849\end{array}$ & $91,102,649,849$ & $51-65,601-614,801-814$ \\
\hline & Xe-132 & 0.26908633 & $1,4,51-67,91,102$ & & \\
\hline & Xe-134 & 0.10435721 & $1,4,51-69,91,102$ & & \\
\hline & Xe-136 & 0.08857344 & $1,4,51-66,91,102$ & & \\
\hline \multirow[t]{3}{*}{$\mathrm{Gd}$} & Gd-152 & 0.00201 & $1,4,51-83,91,102,601-614,649$ & $91,102,649$ & $51-83,601-614$ \\
\hline & Gd-154 & 0.02183 & $\begin{array}{l}1,4,51-76,91,102,601-639,649,801- \\
809,849\end{array}$ & $91,102,649,849$ & $51-76,601-639,801-809$ \\
\hline & Gd-155 & 0.148012 & $1,4,51-88,91,102,601-611,649$ & $91,102,649$ & $51-88,601-611$ \\
\hline
\end{tabular}




\begin{tabular}{|c|c|c|c|c|c|}
\hline Element & Symbol & $\begin{array}{c}\text { Natural } \\
\text { Abundance }\end{array}$ & $M F=3$ & $M F=6$ & $M F=12$ \\
\hline & Gd-156 & 0.20479 & $\begin{array}{l}1,4,51-75,91,102,601-626,649,801- \\
836,849\end{array}$ & $91,102,649,849$ & $51-75,601-626,801-836$ \\
\hline & Gd-157 & 0.15652 & $1,4,51-89,91,102,601-635,649$ & $91,102,649$ & $51-89,601-635$ \\
\hline & Gd-158 & 0.24847 & $1,4,51-77,91,102,649,801-807,849$ & $91,102,649,849$ & $51-77,801-807$ \\
\hline & Gd-160 & 0.218619 & $1,4,51-77,91,102,649,849$ & $91,102,649,849$ & $51-77$ \\
\hline $\mathrm{Bi}$ & $\mathrm{Bi}-209$ & 1 & $1,4-5,51-69,91,102$ & 5 & 102 \\
\hline $\mathrm{Np}$ & Np-237 & 0 & $1,3-4,51-81,91,102$ & 91 & $51-79,102$ \\
\hline $\mathrm{Am}$ & Am-241 & 0 & $1,4,51-88,91,102$ & $51-88,91,102$ & $51-88$ \\
\hline
\end{tabular}


Table D-8. List of available MTs for MF=3, MF=6, and MF=12 in TENDL-2019 for the tier 1 priority elements.

\begin{tabular}{|c|c|c|c|c|c|}
\hline Element & Symbol & $\begin{array}{c}\text { Natural } \\
\text { Abundance }\end{array}$ & $M F=3$ & $\mathrm{MF}=6$ & $\mathrm{MF}=12$ \\
\hline $\mathrm{H}$ & $\mathrm{H}-1$ & 0.9998857 & 1,102 & 102 & \\
\hline $\mathrm{C}$ & $\mathrm{C}-12$ & 0.98938 & $1,3-5,51-62,91,102$ & 5 & 51,102 \\
\hline $\mathrm{N}$ & $\mathrm{N}-14$ & 0.996362 & $\begin{array}{l}\text { 1, 4-5, 51-77, 102, 601-606, 651-653, } \\
701,801-810\end{array}$ & 5 & 102 \\
\hline 0 & $0-16$ & 0.9975716 & $\begin{array}{l}1,4-5,51-57,91,102,601-603,651- \\
669,701-709,749,801-803\end{array}$ & $5,91,749$ & 102 \\
\hline $\mathrm{Na}$ & $\mathrm{Na}-23$ & 1 & $1,3-5,51-79,91,102$ & $5,91,102$ & $51-79$ \\
\hline $\mathrm{Al}$ & Al-27 & 1 & $1,3-5,51-80,91,102$ & $5,91,102$ & $51-66$ \\
\hline \multirow[t]{3}{*}{$\mathrm{Si}$} & Si-28 & 0.9222319 & $1,3-5,51-78,91,102$ & $5,91,102$ & $51-78$ \\
\hline & Si-29 & 0.046858 & $1,3-5,51-79,91,102$ & $5,91,102$ & $51-79$ \\
\hline & Si-30 & 0.0309211 & $1,3-5,51-80,91,102$ & $5,91,102$ & $51-76$ \\
\hline \multirow[t]{4}{*}{$\mathrm{Fe}$} & Fe-54 & 0.0584535 & $1,3-5,51-80,91,102$ & $5,91,102$ & $51-80$ \\
\hline & Fe-56 & 0.9175436 & $1,3-5,51-80,91,102$ & $5,91,102$ & $51-80$ \\
\hline & Fe-57 & 0.021191 & $1,3-5,51-80,91,102$ & $5,91,102$ & $51-80$ \\
\hline & Fe-58 & 0.002824 & $1,3-5,51-80,91,102$ & $5,91,102$ & $51-80$ \\
\hline \multirow[t]{2}{*}{$\mathrm{Cu}$} & $\mathrm{Cu}-63$ & 0.691515 & $1,3-5,51-80,91,102$ & $5,91,102$ & $51-80$ \\
\hline & $\mathrm{Cu}-65$ & 0.308515 & $1,3-5,51-80,91,102$ & $5,91,102$ & $51-80$ \\
\hline \multirow[t]{5}{*}{ W } & W-180 & 0.00121 & $1,3-5,51-80,91,102$ & $5,91,102$ & $51-80$ \\
\hline & W-182 & 0.265016 & $1,3-5,51-80,91,102$ & $5,91,102$ & $51-80$ \\
\hline & W-183 & 0.14314 & $1,3-5,51-80,91,102$ & $5,91,102$ & $51-80$ \\
\hline & W-184 & 0.30642 & $1,3-5,51-80,91,102$ & $5,91,102$ & $51-80$ \\
\hline & W-186 & 0.284319 & $1,3-5,51-80,91,102$ & $5,91,102$ & $51-80$ \\
\hline \multirow[t]{4}{*}{$\mathrm{Pb}$} & $\mathrm{Pb}-204$ & 0.0141 & $1,3-5,51-80,91,102$ & $5,91,102$ & $51-80$ \\
\hline & $\mathrm{Pb}-206$ & 0.2411 & $1,3-5,51-80,91,102$ & $5,91,102$ & $51-80$ \\
\hline & $\mathrm{Pb}-207$ & 0.2211 & $1,3-5,51-80,91,102$ & $5,91,102$ & $51-80$ \\
\hline & $\mathrm{Pb}-208$ & 0.5241 & $1,3-5,51-80,91,102$ & $5,91,102$ & $51-80$ \\
\hline u & U-235 & 0.0072046 & $1,3-5,51-79,91,102$ & $5,51-79,91,102$ & \\
\hline
\end{tabular}




\begin{tabular}{|c|c|c|c|c|c|}
\hline Element & Symbol & $\begin{array}{c}\text { Natural } \\
\text { Abundance }\end{array}$ & $M F=3$ & $M F=6$ & $M F=12$ \\
\hline & U-238 & 0.9927421 & $1,4-5,51-89,91,102,649$ & $5,91,102,649$ & $51-89$ \\
\hline \multirow[t]{2}{*}{$\mathrm{Pu}$} & Pu-239 & 0 & $1,3-4,51-91,102$ & 91,102 & $51-68$ \\
\hline & Pu-240 & 0 & $1,3-5,51-80,91,102$ & $5,91,102$ & $51-80$ \\
\hline
\end{tabular}


Table D-9. List of available MTs for MF=3, MF=6, and MF=12 in TENDL-2019 for the tier 2 priority elements.

\begin{tabular}{|c|c|c|c|c|c|}
\hline Element & Symbol & $\begin{array}{c}\text { Natural } \\
\text { Abundance }\end{array}$ & $\mathrm{MF}=3$ & $M F=6$ & $M F=12$ \\
\hline \multirow[t]{2}{*}{$\mathrm{He}$} & $\mathrm{He}-3$ & 0.000001343 & 1,102 & & \\
\hline & $\mathrm{He}-4$ & 0.999998663 & 1 & & \\
\hline \multirow[t]{2}{*}{ Li } & Li-6 & 0.07594 & $1,4,51-81,102$ & & 57,102 \\
\hline & $\mathrm{Li}-7$ & 0.92414 & $1,4,51-82,102$ & & 51,102 \\
\hline $\mathrm{Be}$ & Be-9 & 1 & $1,3,102,701$ & 701 & 102 \\
\hline \multirow[t]{2}{*}{ B } & $\mathrm{B}-10$ & 0.1997 & $1,3-4,51-85,102,601-605,801$ & 801 & 102 \\
\hline & $\mathrm{B}-11$ & 0.8017 & $1,4,51-60,91,102$ & 91 & 102 \\
\hline \multirow[t]{2}{*}{$\mathrm{Cl}$} & $\mathrm{Cl}-35$ & 0.75761 & $\begin{array}{l}1,3-4,51-80,91,102,601-629,649 \\
651-680,699,701-730,749,801-820 \\
849\end{array}$ & $\begin{array}{l}51-80,91,601-629,649,651-680,699, \\
701-730,749,801-820,849\end{array}$ & 102 \\
\hline & $\mathrm{Cl}-37$ & 0.24241 & $\begin{array}{l}1,3-4,51-77,91,102,649,651-661 \\
699,701-715,749,801-805,849\end{array}$ & $\begin{array}{l}51-77,91,649,651-661,699,701-715, \\
749,801-805,849\end{array}$ & 102 \\
\hline \multirow[t]{4}{*}{$\mathrm{Cr}$} & $\mathrm{Cr}-50$ & 0.0434513 & $1,3-5,51-56,91,102$ & $5,51-56,91$ & $51-56,102$ \\
\hline & $\mathrm{Cr}-52$ & 0.8378918 & $1,3-5,51-60,91,102$ & $5,51-60,91$ & $51-60,102$ \\
\hline & $\mathrm{Cr}-53$ & 0.0950117 & $1,3-5,51-63,91,102$ & $5,51-63,91$ & $51-63,102$ \\
\hline & $\mathrm{Cr}-54$ & 0.023657 & $1,3-5,51-54,91,102$ & $5,51-54,91$ & $51-54,102$ \\
\hline $\mathrm{Mn}$ & $\mathrm{Mn}-55$ & 1 & $\begin{array}{l}\text { 1, 4-5, 51-89, 91, 102, 601-632, 649, } \\
801-831\end{array}$ & $5,91,102,649$ & $51-89,601-632,801-831$ \\
\hline \multirow[t]{5}{*}{$\mathrm{Ni}$} & $\mathrm{Ni}-58$ & 0.6807719 & $1,4-5,51-84,91,102$ & $5,51-84,91,102$ & $51-84$ \\
\hline & $\mathrm{Ni}-60$ & 0.2622315 & $1,4-5,51-79,91,102$ & $5,51-79,91,102$ & $51-79$ \\
\hline & $\mathrm{Ni}-61$ & 0.01139913 & $1,4-5,51-85,91,102$ & $5,51-85,91,102$ & $51-85$ \\
\hline & $\mathrm{Ni}-62$ & 0.0363464 & $1,4-5,51-88,91,102$ & $5,51-88,91,102$ & $51-88$ \\
\hline & $\mathrm{Ni}-64$ & 0.00925519 & $1,4-5,51-88,91,102$ & $5,51-88,91,102$ & $51-88$ \\
\hline Ge & Ge-70 & 0.205727 & $\begin{array}{l}1,4,51-89,91,102,601-619,649,801- \\
839,849\end{array}$ & $91,102,649,849$ & $51-89,601-619,801-839$ \\
\hline
\end{tabular}




\begin{tabular}{|c|c|c|c|c|c|}
\hline Element & Symbol & $\begin{array}{c}\text { Natural } \\
\text { Abundance }\end{array}$ & $\mathrm{MF}=3$ & $M F=6$ & $\mathrm{MF}=12$ \\
\hline & Ge-72 & 0.274532 & $\begin{array}{l}1,4,51-83,91,102,601-614,649,801- \\
827,849\end{array}$ & $91,102,649,849$ & $51-83,601-614,801-827$ \\
\hline & Ge-73 & 0.077512 & $\begin{array}{l}1,4,51-86,91,102,601-622,649,801- \\
837,849\end{array}$ & $91,102,649,849$ & $51-86,601-622,801-837$ \\
\hline & Ge-74 & 0.36502 & $1,4,51-89,91,102,649,801-804,849$ & $91,102,649,849$ & $51-89,801-804$ \\
\hline & Ge-76 & 0.077312 & $1,4,51-89,91,102,601-608,649,849$ & $91,102,649,849$ & $51-89,601-608$ \\
\hline \multirow[t]{2}{*}{$\mathrm{Br}$} & $\mathrm{Br}-79$ & 0.50697 & $1,4,51-79,91,102$ & & \\
\hline & $\mathrm{Br}-81$ & 0.49317 & $1,4,51-76,91,102$ & & \\
\hline \multirow[t]{8}{*}{$\mathrm{Cd}$} & Cd-106 & 0.01256 & $1,4,51-61,91,102$ & & $51-61,91,102$ \\
\hline & $\mathrm{Cd}-108$ & 0.00893 & $1,4,51-60,91,102$ & & \\
\hline & $\mathrm{Cd}-110$ & 0.124918 & $1,4,51-64,91,102$ & & \\
\hline & $\mathrm{Cd}-111$ & 0.128012 & $1,4,51-61,91,102$ & & $51-61,91,102$ \\
\hline & $\mathrm{Cd}-112$ & 0.241321 & $1,4,51-58,91,102$ & & \\
\hline & $\mathrm{Cd}-113$ & 0.122212 & $1,3-4,51-71,91,102$ & & \\
\hline & $\mathrm{Cd}-114$ & 0.287342 & $1,4,51-60,91,102$ & & \\
\hline & $\mathrm{Cd}-116$ & 0.074918 & $1,4,51-56,91,102$ & & \\
\hline 1 & $\mathrm{I}-127$ & 1 & $\begin{array}{l}1,4,51-71,91,102,601-622,649,801 \\
849\end{array}$ & $51-71,91,601-622,649,801,849$ & 102 \\
\hline Cs & Cs-133 & 1 & $\begin{array}{l}1,4,51-64,91,102,601-606,649,801- \\
814,849\end{array}$ & $91,102,649,849$ & $51-64,601-606,801-814$ \\
\hline \multirow[t]{2}{*}{ La } & La-138 & 0.000888171 & $1,4,51-65,91,102$ & & \\
\hline & La-139 & 0.999111971 & $1,4,51-61,91,102$ & & \\
\hline \multirow[t]{4}{*}{$\mathrm{Ce}$} & Ce-136 & 0.001852 & $\begin{array}{l}1,4,51-56,91,102,601-608,649,801- \\
811,849\end{array}$ & $91,102,649,849$ & $51-56,601-608,801-811$ \\
\hline & Ce-138 & 0.002512 & $\begin{array}{l}1,4,51-64,91,102,601-610,649,801- \\
810,849\end{array}$ & $91,102,649,849$ & $51-64,601-610,801-810$ \\
\hline & Ce-140 & 0.8845051 & $1,4,51-73,91,102$ & & \\
\hline & Ce-142 & 0.1111451 & $1,4,51-59,91,102$ & & \\
\hline
\end{tabular}


Table D-10. List of available MTs for MF=3, MF=6, and MF=12 in TENDL-2019 for the tier 3 priority elements.

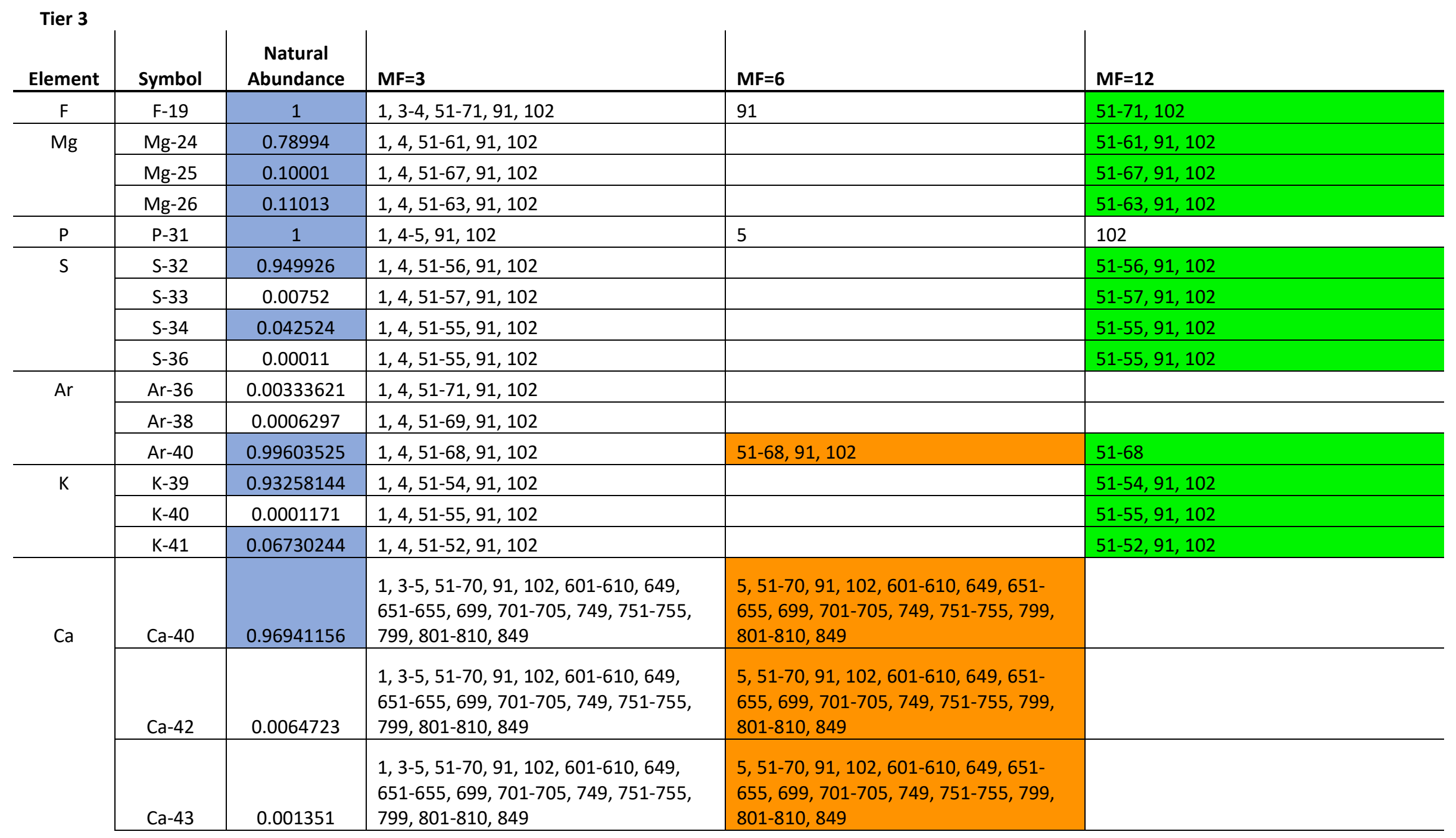




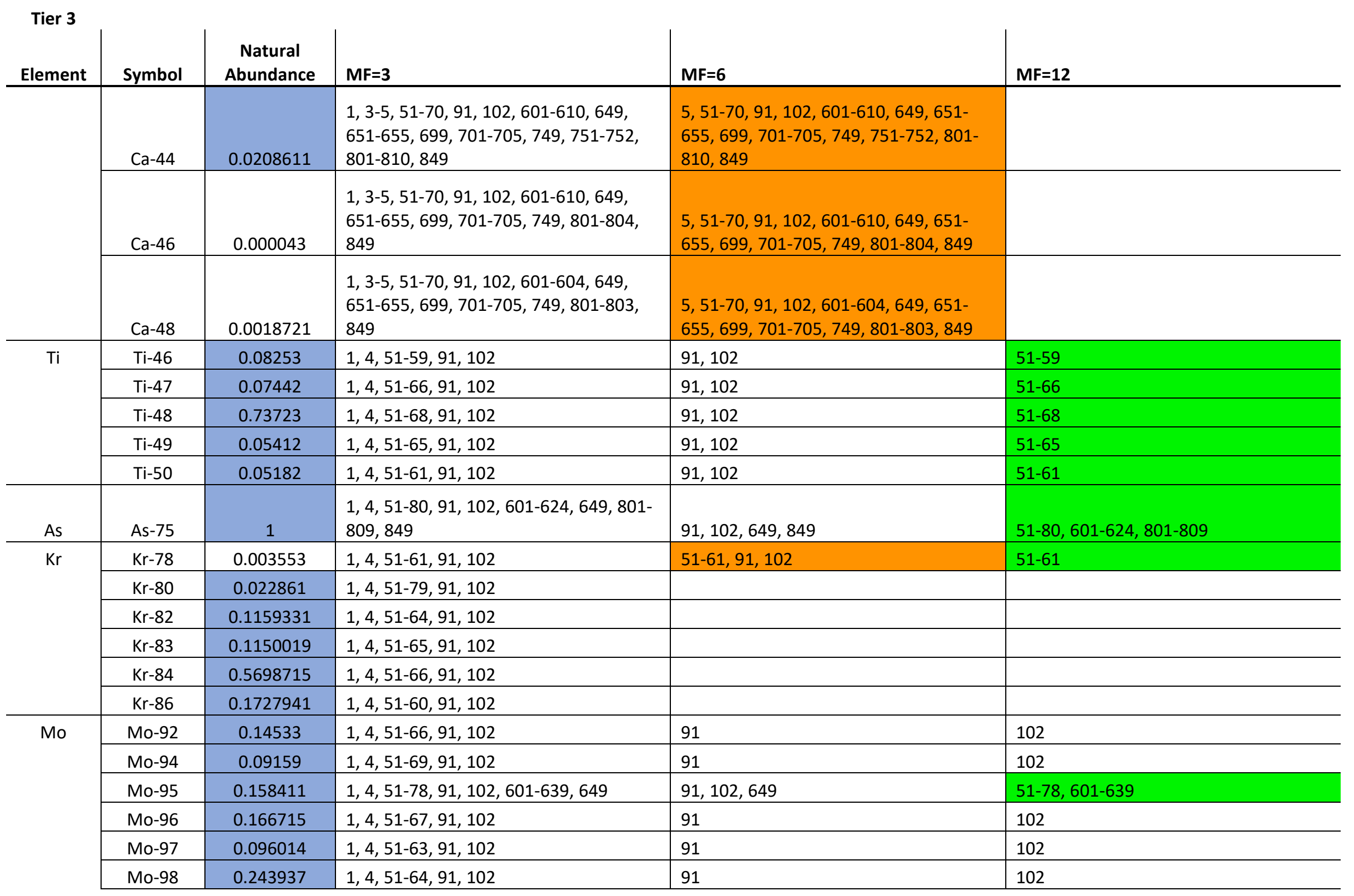




\begin{tabular}{|c|c|c|c|c|c|}
\hline Element & Symbol & $\begin{array}{c}\text { Natural } \\
\text { Abundance }\end{array}$ & $\mathrm{MF}=3$ & $M F=6$ & $\mathrm{MF}=12$ \\
\hline & Mo-100 & 0.098231 & $1,4,51-57,91,102$ & & \\
\hline \multirow[t]{10}{*}{$\mathrm{Sn}$} & Sn-112 & 0.00971 & $1,4,51-73,91,102$ & & \\
\hline & Sn-114 & 0.00661 & $1,4,51-76,91,102$ & & \\
\hline & Sn-115 & 0.00341 & $1,4,51-66,91,102$ & & \\
\hline & Sn-116 & 0.14549 & $1,4,51-60,91,102$ & & \\
\hline & Sn-117 & 0.07687 & $1,4,51-62,91,102$ & & \\
\hline & Sn-118 & 0.24229 & $1,4,51-57,91,102$ & & \\
\hline & Sn-119 & 0.08594 & $1,4,51-70,91,102$ & & \\
\hline & Sn-120 & 0.32589 & $1,4,51-79,91,102$ & $51-79,91,102$ & $51-79$ \\
\hline & Sn-122 & 0.04633 & $1,4,51-59,91,102$ & & \\
\hline & Sn-124 & 0.05795 & $1,4,51-70,91,102$ & & \\
\hline \multirow[t]{2}{*}{$\mathrm{Sb}$} & Sb-121 & 0.57215 & $1,3-4,51-58,91,102$ & & \\
\hline & Sb-123 & 0.42795 & $1,3-4,51-56,91,102$ & & \\
\hline \multirow[t]{9}{*}{$\mathrm{Xe}$} & Xe-124 & 0.0009523 & $1,4,51-59,91,102$ & $51-59,91,102$ & $51-59$ \\
\hline & Xe-126 & 0.0008902 & $1,4,51-65,91,102$ & & \\
\hline & Xe-128 & 0.0191028 & $1,4,51-73,91,102$ & & \\
\hline & Xe-129 & 0.26400682 & $1,4,51-66,91,102$ & & \\
\hline & Xe-130 & 0.04071013 & $1,4,51-56,91,102$ & & \\
\hline & Xe-131 & 0.2123243 & $\begin{array}{l}1,4,51-65,91,102,601-614,649,801- \\
814,849\end{array}$ & $91,102,649,849$ & $51-65,601-614,801-814$ \\
\hline & Xe-132 & 0.26908633 & $1,4,51-67,91,102$ & & \\
\hline & Xe-134 & 0.10435721 & $1,4,51-69,91,102$ & & \\
\hline & Xe-136 & 0.08857344 & $1,4,51-66,91,102$ & & \\
\hline \multirow[t]{3}{*}{$\mathrm{Gd}$} & Gd-152 & 0.00201 & $1,4,51-83,91,102,601-614,649$ & $91,102,649$ & $51-83,601-614$ \\
\hline & Gd-154 & 0.02183 & $\begin{array}{l}1,4,51-76,91,102,601-639,649,801- \\
809,849\end{array}$ & $91,102,649,849$ & $51-76,601-639,801-809$ \\
\hline & Gd-155 & 0.148012 & $1,4,51-88,91,102,601-611,649$ & $91,102,649$ & $51-88,601-611$ \\
\hline
\end{tabular}




\begin{tabular}{|c|c|c|c|c|c|}
\hline Element & Symbol & $\begin{array}{c}\text { Natural } \\
\text { Abundance }\end{array}$ & $M F=3$ & $M F=6$ & $M F=12$ \\
\hline & Gd-156 & 0.20479 & $\begin{array}{l}1,4,51-75,91,102,601-626,649,801- \\
836,849\end{array}$ & $91,102,649,849$ & $51-75,601-626,801-836$ \\
\hline & Gd-157 & 0.15652 & $1,4,51-89,91,102,601-635,649$ & $91,102,649$ & $51-89,601-635$ \\
\hline & Gd-158 & 0.24847 & $1,4,51-77,91,102,649,801-807,849$ & $91,102,649,849$ & $51-77,801-807$ \\
\hline & Gd-160 & 0.218619 & $1,4,51-77,91,102,649,849$ & $91,102,649,849$ & $51-77$ \\
\hline $\mathrm{Bi}$ & $\mathrm{Bi}-209$ & 1 & $1,4-5,51-69,91,102$ & 5 & 102 \\
\hline $\mathrm{Np}$ & $\mathrm{Np}-237$ & 0 & $1,3-4,51-81,91,102$ & 91 & $51-79,102$ \\
\hline $\mathrm{Am}$ & Am-241 & 0 & $1,4,51-88,91,102$ & $51-88,91,102$ & $51-88$ \\
\hline
\end{tabular}


Table D-11. Breakup reaction flags in the ENDF libraries.

\begin{tabular}{|c|c|c|c|c|c|}
\hline Target & LR Flag & Emitted particles & Residual & MT & Libraries \\
\hline \multirow[t]{2}{*}{${ }^{6} \mathbf{L i}$} & \multirow[t]{2}{*}{32} & \multirow[t]{2}{*}{ deuteron } & \multirow[t]{2}{*}{${ }^{4} \mathrm{He}$} & $51-81$ & ENDF/B-VIII.0, BROND-3.1, CENDL-3.1, JEFF-3.3, TENDL-2019 \\
\hline & & & & $51-86$ & JENDL-4.0 \\
\hline \multirow[t]{2}{*}{${ }^{7} \mathbf{L i}$} & \multirow[t]{2}{*}{33} & \multirow[t]{2}{*}{ triton } & \multirow[t]{2}{*}{${ }^{4} \mathrm{He}$} & $52-82$ & ENDF/B-VIII.0, BROND-3.1, CENDL-3.1, JEFF-3.3, TENDL-2019 \\
\hline & & & & $52-84$ & CENDL-3.1, JENDL-4.0 \\
\hline \multirow[t]{4}{*}{${ }^{10} B$} & 22 & alpha & ${ }^{6} \mathrm{Li}$ & $\begin{array}{l}55-56,58-61,63,66-67,69,72 \\
75,82,85\end{array}$ & ENDF/B-VIII.0, BROND-3.1, JEFF-3.3, TENDL-2019 \\
\hline & 28 & proton & ${ }^{9} \mathrm{Be}$ & 65,78 & ENDF/B-VIII.0, BROND-3.1, JEFF-3.3, TENDL-2019 \\
\hline & \multirow[t]{2}{*}{35} & \multirow[t]{2}{*}{ deuteron +2 alphas } & \multirow[t]{2}{*}{ None } & $\begin{array}{l}62,64,68,70-71,73-74,76-77, \\
79-81,83-84\end{array}$ & ENDF/B-VIII.0, BROND-3.1, JEFF-3.3, TENDL-2019 \\
\hline & & & & $60-89$ & JENDL-4.0 \\
\hline \multirow[t]{3}{*}{${ }^{12} \mathrm{C}$} & \multirow[t]{3}{*}{23} & \multirow[t]{3}{*}{3 alphas } & \multirow[t]{3}{*}{ None } & $52-62,91$ & ENDF/B-VIII.0, BROND-3.1, JEFF-3.3, TENDL-2019 \\
\hline & & & & $52-53$ & CENDL-3.1 \\
\hline & & & & $52-75,91$ & JENDL-4.0 \\
\hline${ }^{14} \mathbf{N}$ & 28 & proton & ${ }^{13} \mathrm{C}$ & $60-61,63-77$ & ENDF/B-VIII.0, BROND-3.1, JEFF-3.3, TENDL-2019 \\
\hline \multirow[t]{4}{*}{${ }^{16} 0$} & \multirow[t]{2}{*}{22} & \multirow[t]{2}{*}{ alpha } & \multirow[t]{2}{*}{${ }^{12} \mathrm{C}$} & $58-59$ & CENDL-3.1 \\
\hline & & & & $55-79$ & JENDL-4.0 \\
\hline & 28 & proton & ${ }^{15} \mathrm{~N}$ & 91 & JENDL-4.0 \\
\hline & 40 & electron-positron pair & ${ }^{16} 0$ & 51 & JENDL-4.0 \\
\hline
\end{tabular}

